\title{
Alternate-Fueled Combustor-Sector Performance-Part A: Combustor Performance and Part B: Combustor Emissions
}

\author{
D. T. Shouse, ${ }^{1}$ C. Neuroth, ${ }^{1}$ R. C. Hendricks, ${ }^{2}$ A. Lynch, ${ }^{1}$ C. W. Frayne, ${ }^{1}$ J. S. Stutrud, ${ }^{1}$ \\ E. Corporan, ${ }^{1}$ and Capt. T. Hankins ${ }^{1}$ \\ ${ }^{1}$ Turbine Engine Division, Combustor Group, AFRL, Wright-Patterson Air Force Base (WPAFB), OH 45433, USA \\ ${ }^{2}$ Research and Technology Directorate, NASA Glenn Research Center, 21000 Brookpark Road, Cleveland, OH 44135, USA
}

Correspondence should be addressed to R. C. Hendricks, robert.c.hendricks@grc.nasa.gov

Received 23 August 2011; Accepted 21 September 2011

Academic Editor: C. Del Vecchio

Copyright (C) 2012 D. T. Shouse et al. This is an open access article distributed under the Creative Commons Attribution License, which permits unrestricted use, distribution, and reproduction in any medium, provided the original work is properly cited.

\begin{abstract}
Alternate aviation fuels for military or commercial use are required to satisfy MIL-DTL-83133F or ASTM D 7566 standards, respectively, and are classified as "drop-in" fuel replacements. To satisfy legacy issues, blends to 50\% alternate fuel with petroleum fuels are acceptable. Adherence to alternate fuels and fuel blends requires "smart fueling systems" or advanced fuel-flexible systems, including combustors and engines, without significant sacrifice in performance or emissions requirements. This paper provides preliminary performance and emissions and particulates combustor sector data. The data are for nominal inlet conditions at 225 psia and $800^{\circ} \mathrm{F}(1.551 \mathrm{MPa}$ and $700 \mathrm{~K})$, for synthetic-paraffinic-kerosene- (SPK-) type (Fisher-Tropsch (FT)) fuel and blends with JP-8+100 relative to JP-8+100 as baseline fueling. Assessments are made of the change in combustor efficiency, wall temperatures, emissions, and luminosity with SPK of $0 \%, 50 \%$, and $100 \%$ fueling composition at $3 \%$ combustor pressure drop. The performance results (Part A) indicate no quantifiable differences in combustor efficiency, a general trend to lower liner and higher core flow temperatures with increased FT fuel blends. In general, emissions data (Part B) show little differences, but, with percent increase in FT-SPK-type fueling, particulate emissions and wall temperatures are less than with baseline JP-8. High-speed photography.
\end{abstract}

\section{Introduction}

Synthetic and biomass fueling are now considered as nearterm aviation alternate fueling. The major impediment is a secure sustainable supply of these fuels at reasonable cost. Alternate aviation fuels are currently required to satisfy MILDTL-83133F for Fisher-Tropsch- (FT-) equivalent processed ASTM D 7566 and known as "drop-in" fuel replacements (military and civil, resp.). As in aviation, many land-based and marine power generation systems are elderly, known as the legacy issue. Fueling these systems requires careful compliance to the fuel handling and engine systems for which they were (are) designed. To satisfy a sustainable fuel supply, it will be necessary to accept fuels derived from a variety of feedstocks. Consequently, adherence to alternate fuels and fuel blends requires "smart fueling systems" or advanced fuel-flexible systems, including combustors and engines, without significant sacrifice in performance or emissions requirements.
The common military services fueling concept is that JP$8+100$ or alternate FT-type fuels that can fuel gas turbines as well as many diesel systems. Diesel biomass-derived oils are often unsuitable because sufficient aromatics and sulfur are lacking, which provide lubricity, thus reducing design component life. To counter these issues, additives are promoted.

This paper provides preliminary performance, luminosity, emissions, and particulates combustor sector data relative to JP-8+100 as baseline fueling, for synthetic-paraffinickerosene- (SPK-) type fuel blends (herein FT-type fuel) and projections for testing of biofuel fuel blends leading to preliminary development of smart fueling (fuel flexible) and combustor systems for the next generation aeronautic and aeronautic-derivative gas turbine engines. Fuel flexibility is an engine operations goal to enable various designer fuels operations with minor alterations in controller function or geometry. 

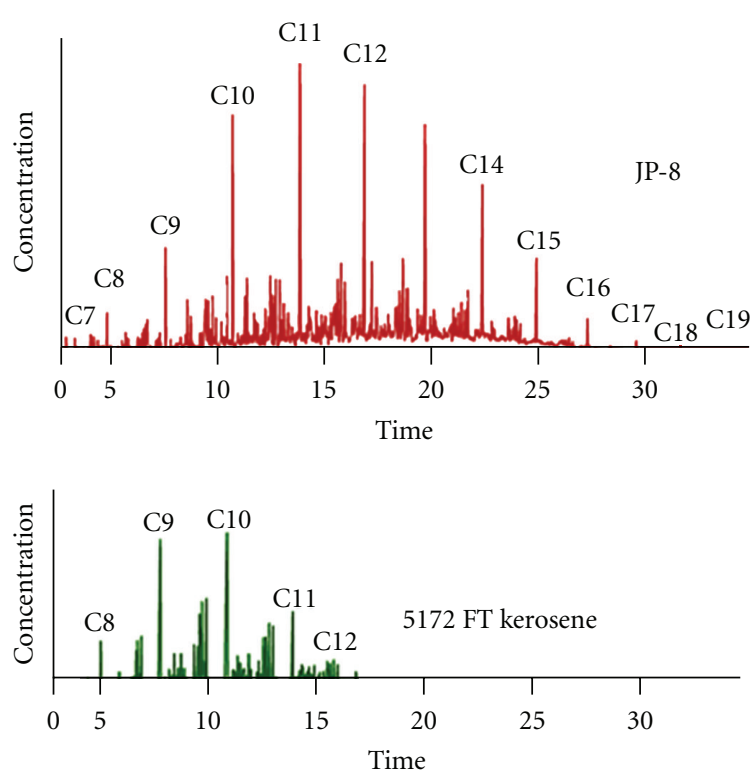

(a)

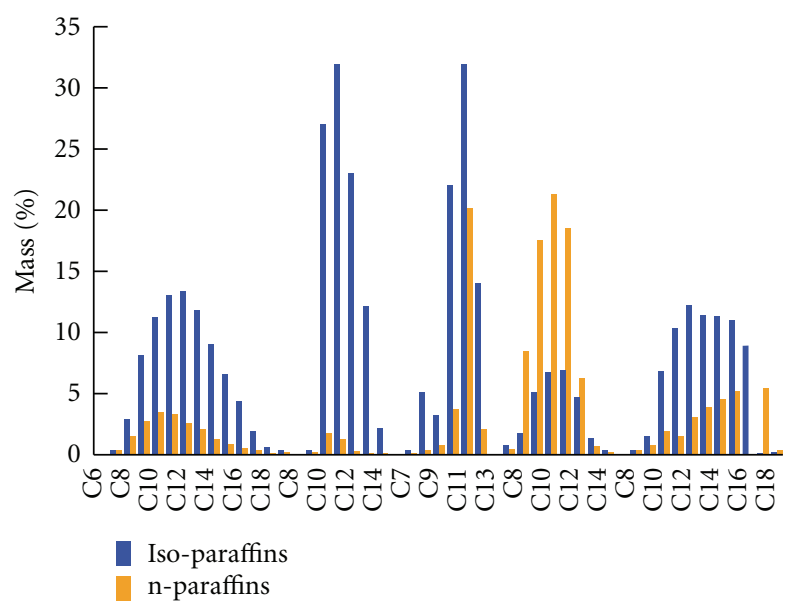

(b)

Figure 1: (a) Representative carbon distributions for JP-8 and AFRL no. 5172 FT (SPK) from shell gas-to-liquid (GTL) with $0 \%$ aromatics and $0 \%$ sulfur. The JP- 8 cited is $19 \%$ aromatics and $1200 \mathrm{ppm}$ sulfur. (b) Variations in representative carbon distributions for proposed alternate fuels with high and low n-paraffinic to isomer ratios.

Truly performance and emissions are coupled issues; however, combustor performance will be presented in Part A and combustor emissions as Part B for understanding both in sufficient detail.

Herein, fueling acronyms are synthetic paraffinic kerosene (SPK) and hydro-treated renewable jet (HRJ) also known as bio-SPK or (SPK from hydroprocessed esters and fatty acids) SPK-HEFA and proposed as ASTM D 7566Annex-1.

\section{Part A: Combustor Performance}

Part A presents fueling characteristics, facility development, and operation followed by thermal performance of the

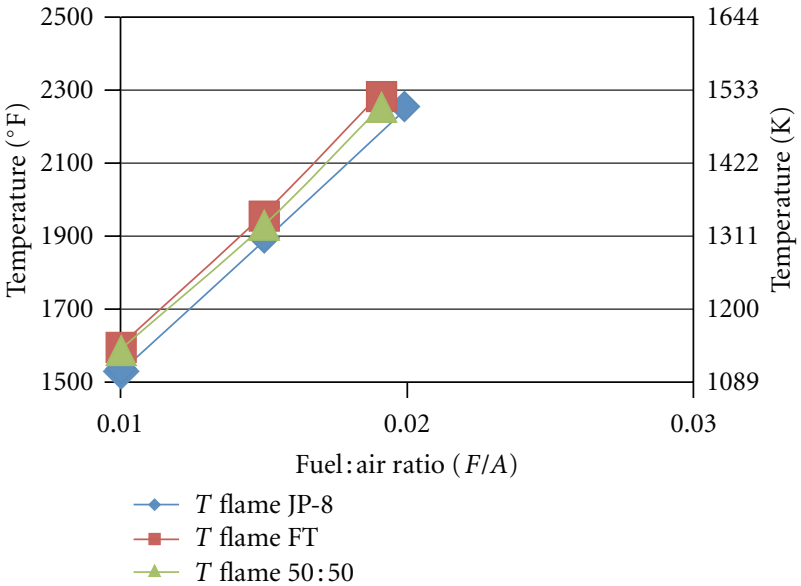

FIGURE 2: Calculated flame temperature variation with $F / A$ and fuel composition.

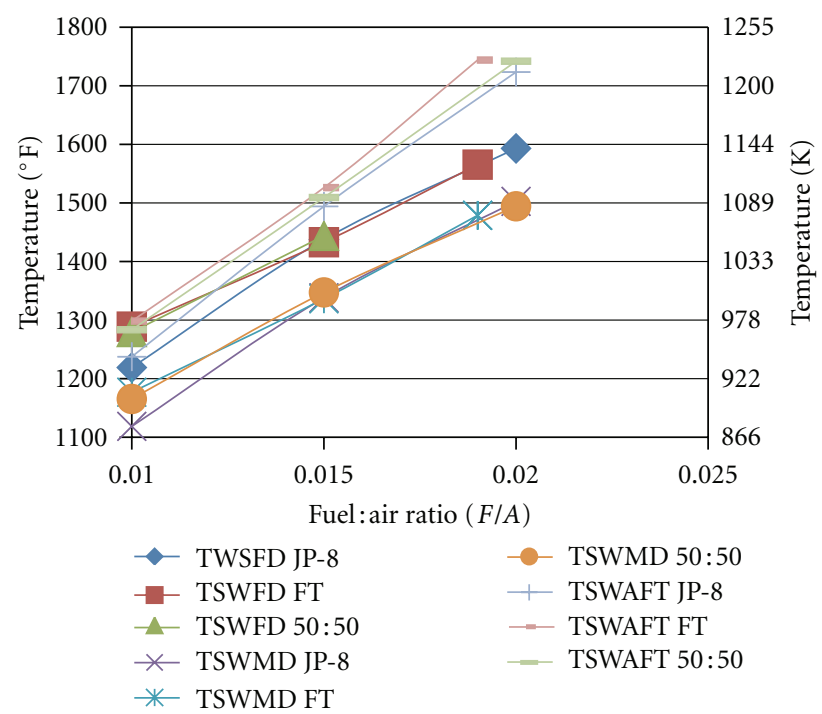

FIGURE 3: Sidewall temperature variation with $F / A$ and fuel composition.

combustor and combustor visualization. The results are for one of several combustors-herein denoted as combustor A-to be evaluated in development of fuel-flexible engine combustors.

Most data herein are testing at nominal inlet conditions of 225 psia and $800^{\circ} \mathrm{F}(1.55 \mathrm{MPa}, 700 \mathrm{~K})$ at $3 \%$ combustor pressure drop, where JP- $8+100$ (JP-8) is taken as baseline. Selected emissions data are provided at and below 225 psia (1.55 MPa).

2.1. Fuel Characteristics. In general, all alternate fueling is required to meet or exceed MIL-DTL-83133F or ASTM D 7566 and Annex 1 requirements. The carbon distribution for each fuel used and primary characteristics differ depending on feedstock source and distilling practices, yet all fall within specification. Typical C-distributions for JP-8 and 


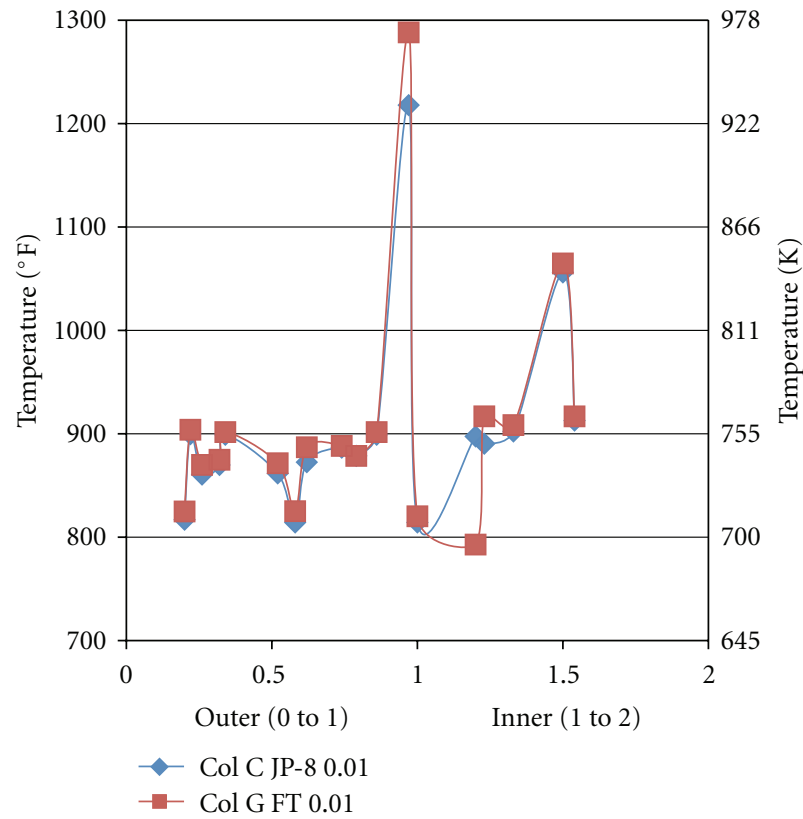

(a)

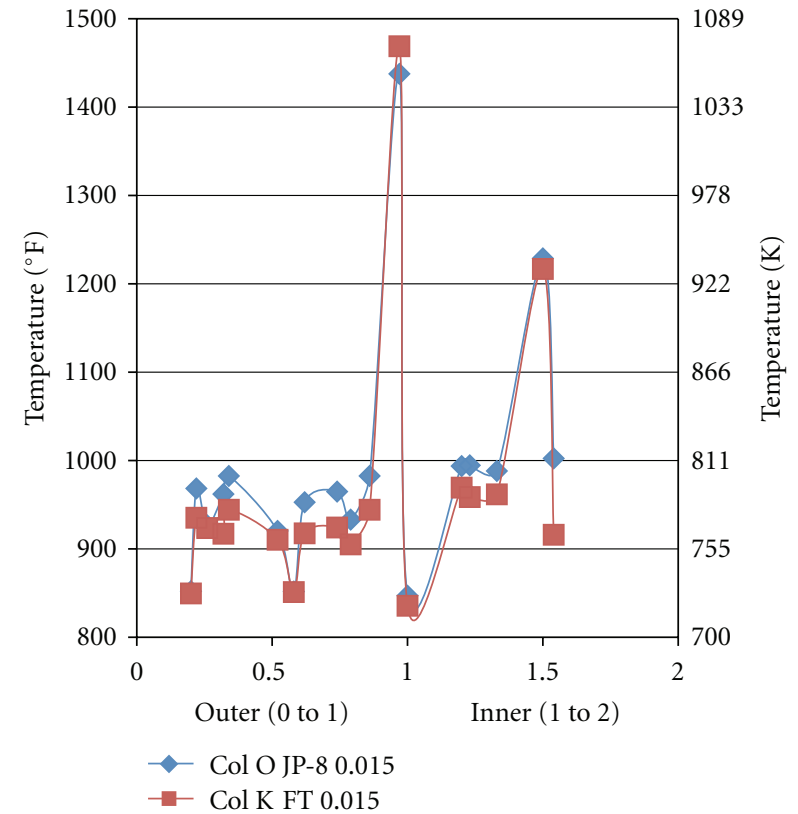

(b)

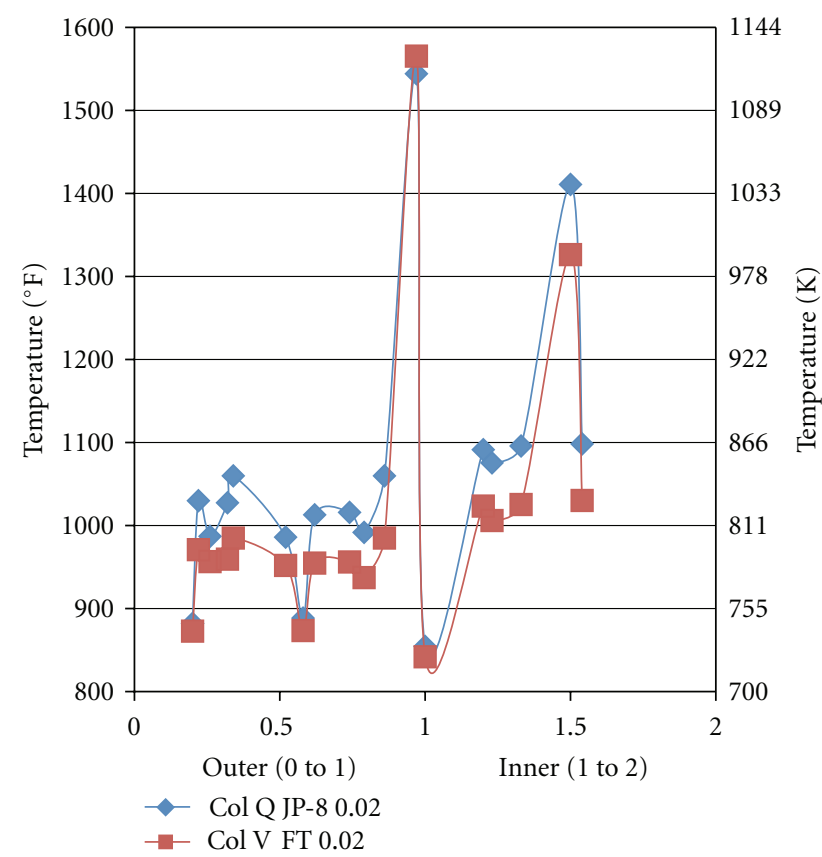

(c)

FIgURE 4: (a) Unwrapped liner temperatures for $F / A=0.010$ and fueling compositions JP-8 and FT. Normalized combustor liner thermocouple locations 0 to 1 outer and 1 to 2 inner. (b) Unwrapped liner temperatures for $F / A=0.015$ and fueling compositions JP-8 and FT. Normalized combustor liner thermocouple locations 0 to 1 outer and 1 to 2 inner. (c) Unwrapped liner temperatures for $F / A \sim 0.020$ and fueling compositions JP-8 and FT. Normalized combustor liner thermocouple locations 0 to 1 outer and 1 to 2 inner.

an (SPK) FT-derived fuel are shown in Figure 1(a) with vendor variations in fuels illustrated in Figure 1(b). Secondary refining of petroleum-based kerosene fuels can also satisfy specifications.

The specifications for one of the fuels, AFRL number 5172 Shell GTL-SPK (FT), are presented in Appendix A.
While fuels purchased by Defense Energy Support Center (DESC) are within specification, independent of whether petroleum- or alternate-based fuels, batch-to-batch variations do occur depending on processors, feedstock, production date, and location of fuel production a world-wide fuels sourcing problem. 


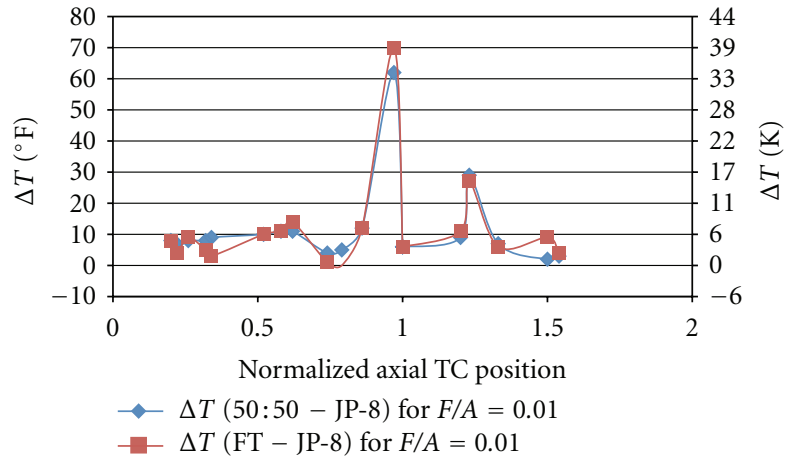

(a)

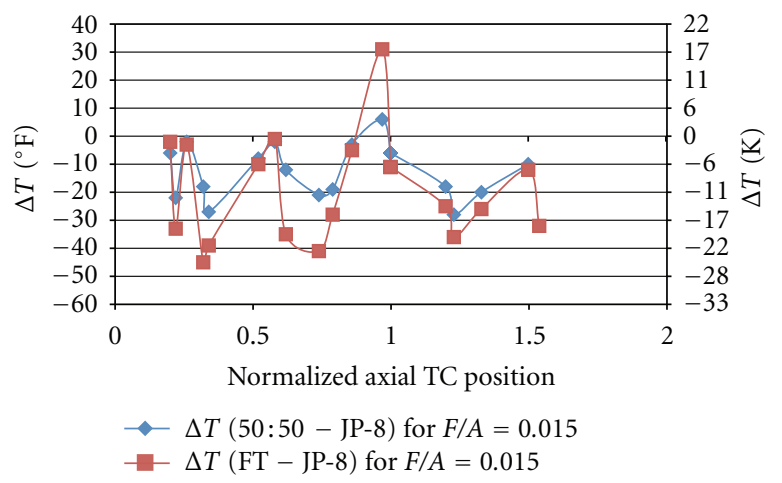

(b)

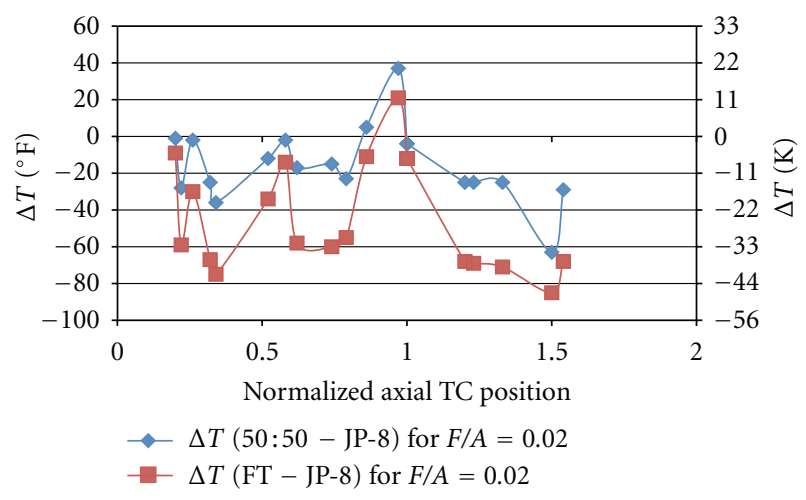

(c)

Figure 5: (a) Unwrapped liner temperature differences $\Delta T$ $\left(T_{\text {fuel blend }}-T_{\text {JP- } 8}\right)$ for $F / A=0.010$ and fueling compositions $50: 50$ and FT. Normalized combustor liner thermocouple locations 0 to 1 outer and 1 to 2 inner. JP-8 difference is 0 . (b) Unwrapped liner temperature differences $\Delta T\left(T_{\text {fuel blend }}-T_{\text {JP- } 8}\right)$ for $F / A=0.015$ and fueling compositions JP-8 and FT. Normalized combustor liner thermocouple locations 0 to 1 outer and 1 to 2 inner. JP-8 difference is 0 . (c) Unwrapped liner temperature differences $\Delta T$ ( $T_{\text {fuel blend }}-$ $T_{\text {JP- } 8}$ ) for $F / A \sim 0.020$ and fueling compositions 50:50 and FT. Normalized combustor liner thermocouple locations 0 to 1 outer and 1 to 2 inner. JP-8 difference is 0 .

2.2. Combustor and Facility Characteristics. The general description of the combustor and supporting research cell data are similar to those reported in Hendricks et al. [4]. The particular aspects of the geometry tested are proprietary and will not be discussed herein. Details of the High Pressure

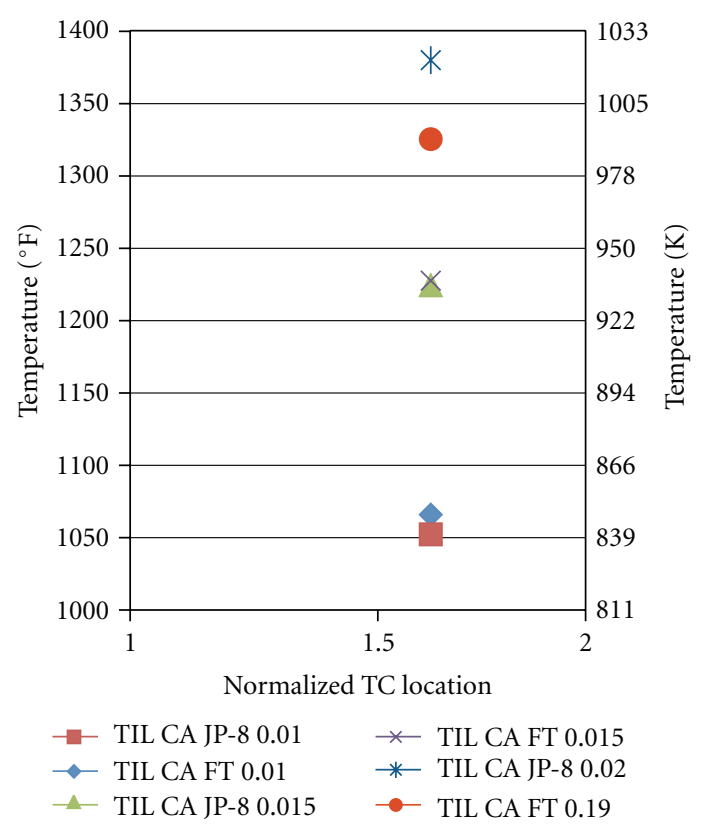

FIGURE 6: Peak inner liner temperatures (TIL) at normalized location 1.5.

Combustion Research Facility at the Air Force Research Laboratory (AFRL) are provided by Shouse et al. [1].

Although some general aspects of the fuel delivery system and operations of the facility are similar to those of $[1,4]$, specific facility modifications and increased capability to handle fuel blending had to be made, including remote alternate test fuel storage/tankage and delivery of the alternate test fuel to the facility fuel pumps, flow meters, and control systems (see Appendix B).

2.2.1. Facility Development. Before validation data could be taken, it was necessary to learn what it takes to conduct high-pressure combustor testing of alternate fuels such as FT and biomass feedstock fuels. It is first necessary to establish the combustion parameters required by the study such as operability, performance, durability time-dependent measurements such as flame studies, and others. Next, an assessment of the effects of pressure ratios and inlet temperatures on both the combustor sector model and desired data was undertaken as well as most importantly, how to safely blend the fuels. The blending system, while complex, enables operations to establish and stabilize combustor inlet pressures and temperatures of preheated air at the required test condition without the additional complication of simultaneously establishing fuel blend.

To establish the fuel delivery system, questions such as how much fuel and time are required to fully evaluate a typical fuel candidate must be resolved. A 500-gal trailermounted fuel tank was chosen for porting alternative fuels with the added feature of coupling to the facility fueling system. The facility has two duplicate fuel systems that provided a means of handling JP-8 fuel with one system to pump, meter, and control the JP- 8 fuel; this system is referred 

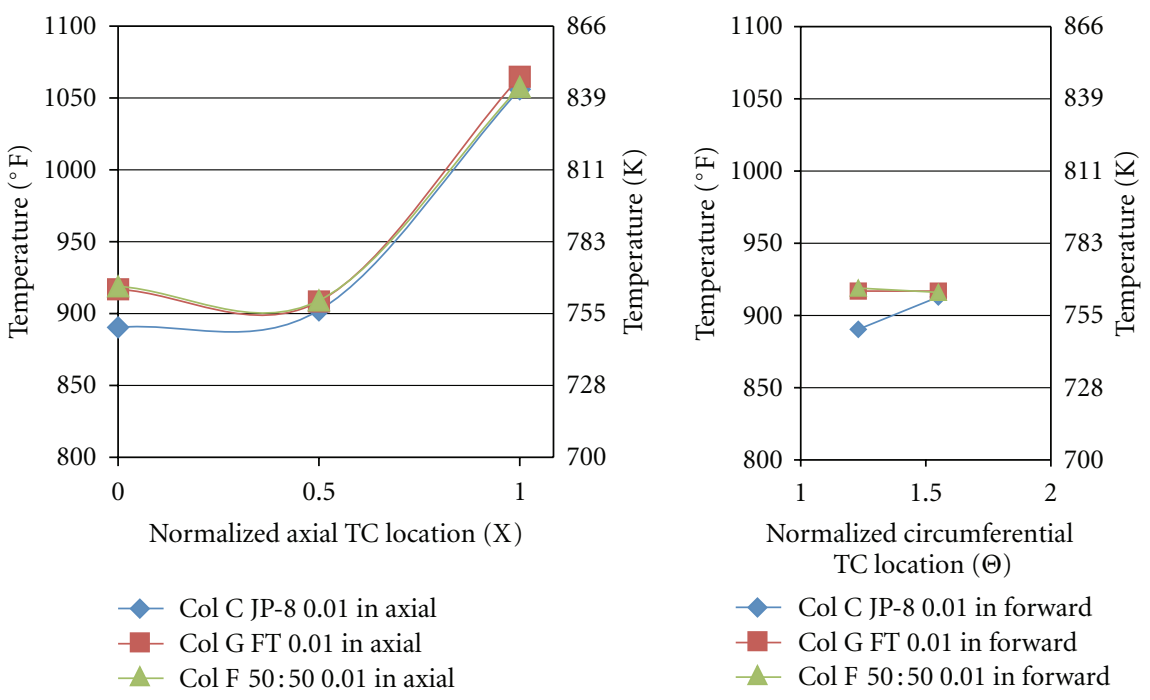

Normalized circumferential

TC location $(\Theta)$

$\checkmark$ Col C JP-8 0.01 in forward

- Col G FT 0.01 in forward

-C Col F 50:50 0.01 in forward
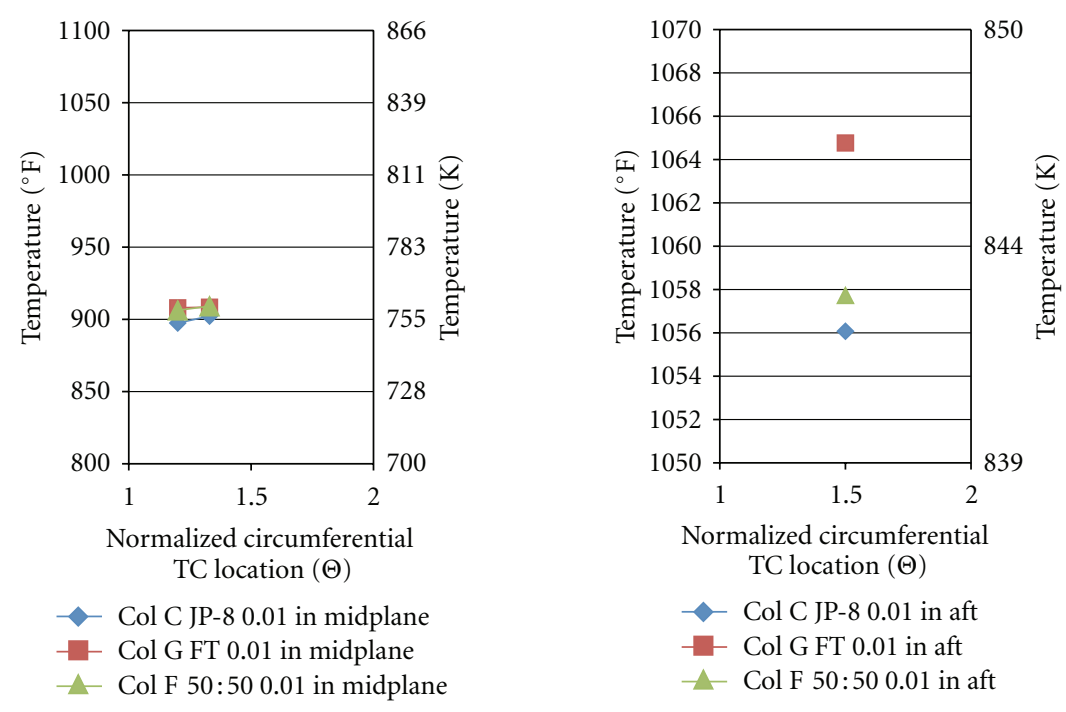

Normalized circumferential TC location $(\Theta)$

$\neg-$ Col C JP-8 0.01 in aft

- Col G FT $0.01 \mathrm{in} \mathrm{aft}$

$\triangle$ Col F 50:50 0.01 in aft

(a)
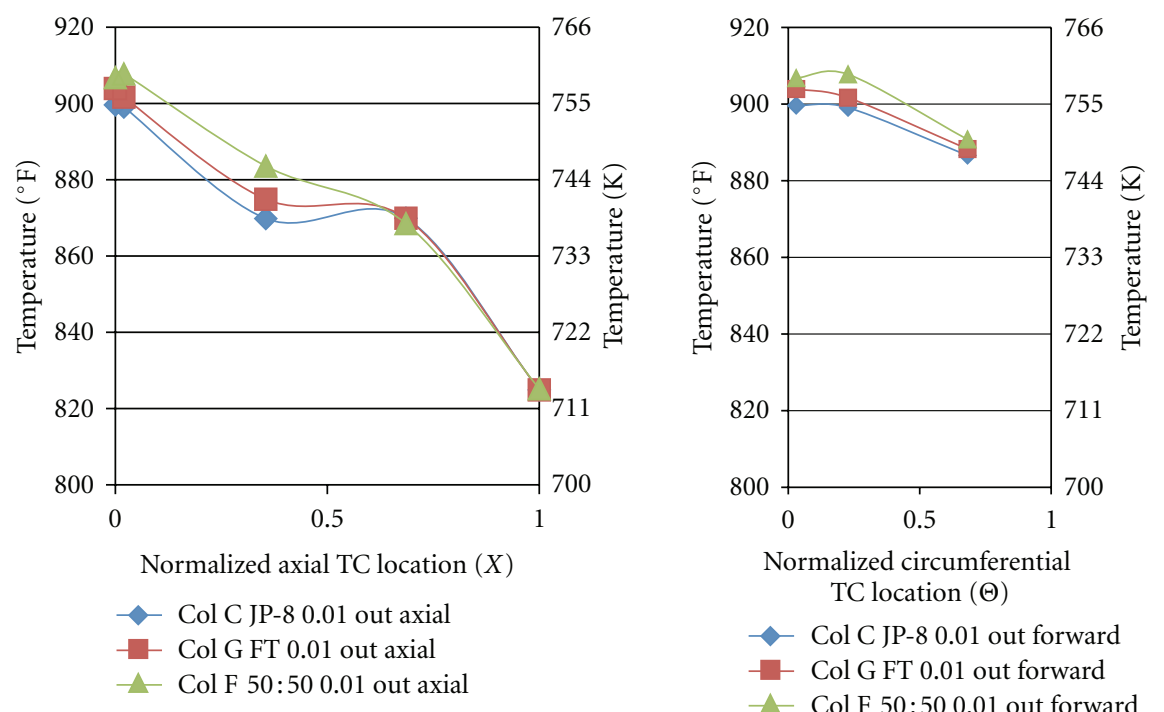

Normalized circumferential

TC location $(\Theta)$

$\checkmark-$ Col C JP-8 0.01 out forward

-Col G FT 0.01 out forward

- Col F 50:50 0.01 out forward

(b) continued

Figure 7: Continued. 


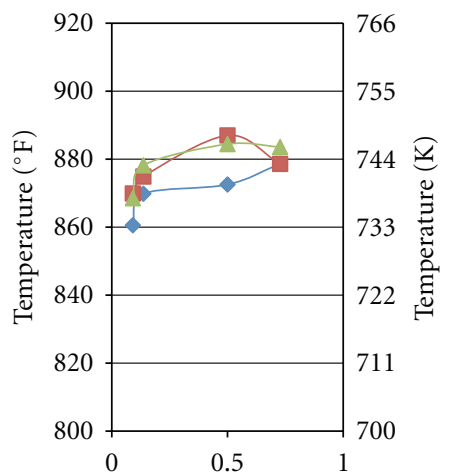

Normalized circumferential TC location $(\Theta)$

$\checkmark$ Col C JP-8 0.01 out midplane

- Col G FT 0.01 out midplane

- Col F 50:50 0.01 out midplane

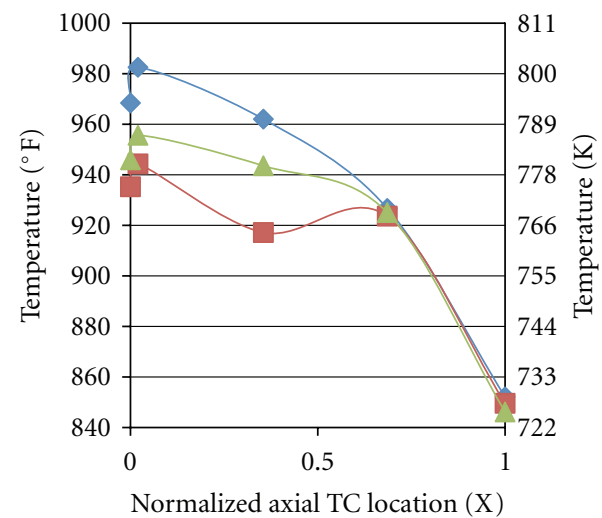

Normalized axial TC location (X)

$\checkmark$ Col O JP-8 0.015 out axial

Col K FT 0.015 out axial

Col M 50:50 0.015 out axial

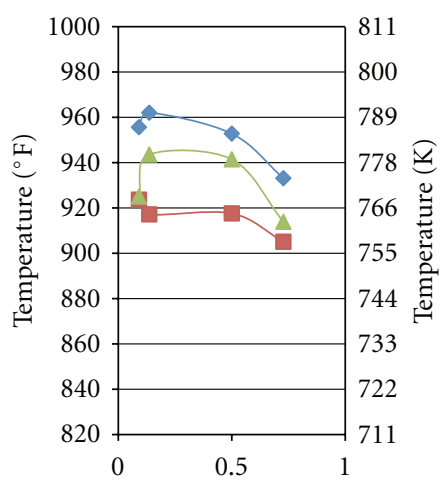

Normalized circumferential

TC location $(\Theta)$

$\checkmark$ Col O JP-8 0.015 out midplane

- Col K FT 0.015 out midplane

- Col M 50:50 0.015 out midplane

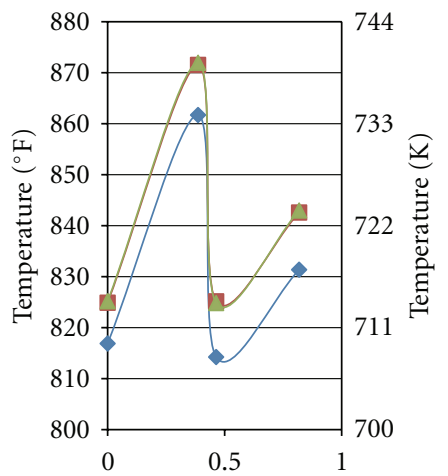

Normalized circumferential

TC location $(\Theta)$

$\checkmark$ Col C JP-8 0.01 out aft

- Col G FT 0.01 out aft

- Col F 50:50 0.01 out aft

(b)

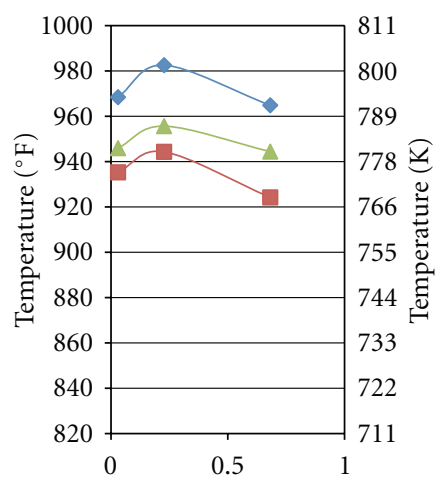

Normalized circumferential

TC location $(\Theta)$

Col O JP-8 0.015 out forward

- - Col K FT 0.015 out forward

- Col M 50:50 0.015 out forward

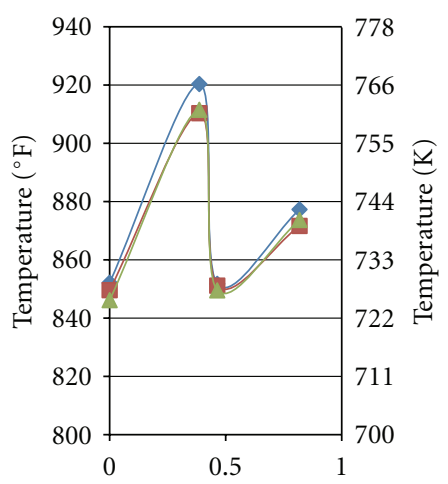

Normalized circumferential

TC location $(\Theta)$

- Col O JP-8 0.015 out aft

Col K FT 0.015 out aft

_ Col M 50:50 0.015 out aft

(c)

FIgURE 7: Continued. 

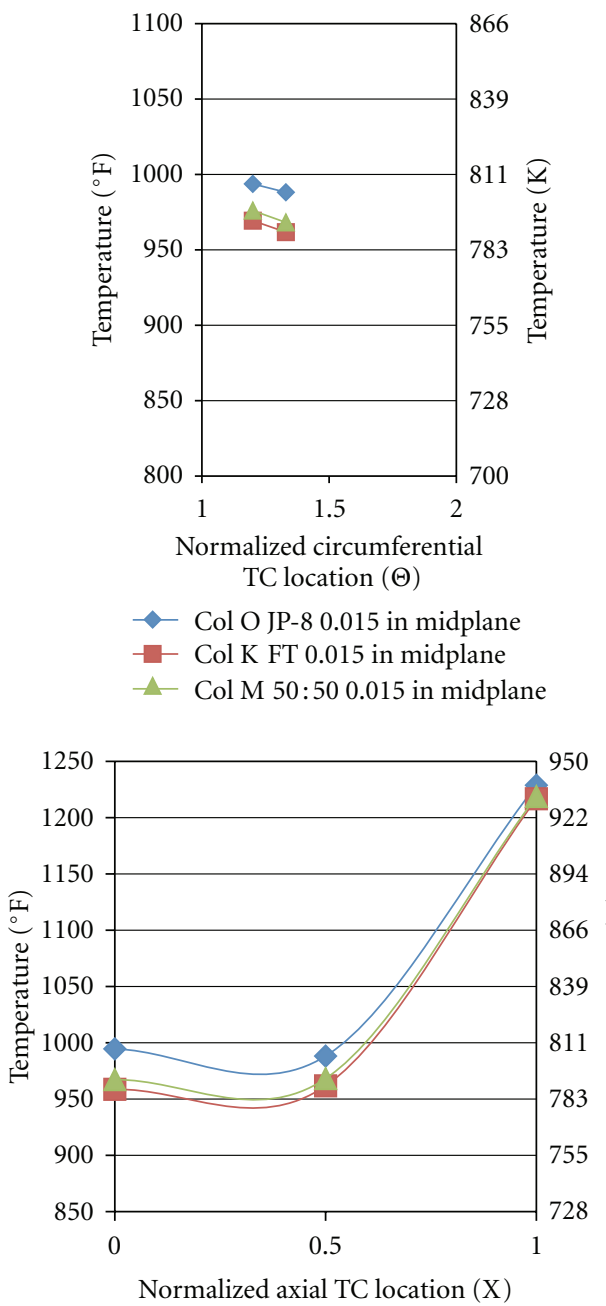

Col O JP-8 0.015 in axia

Col K FT 0.015 in axial

- Col M 50:50 0.015 in axial

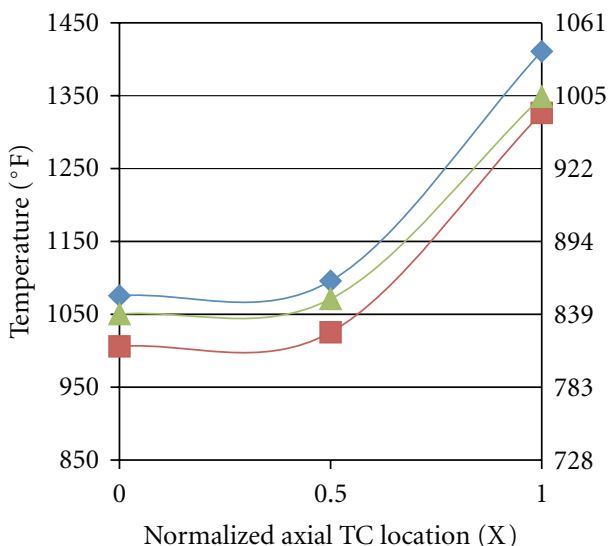

Col Q JP-8 0.02 in axial

Col V FT 0.02 in axial

- Col T 50:50 0.02 in axial

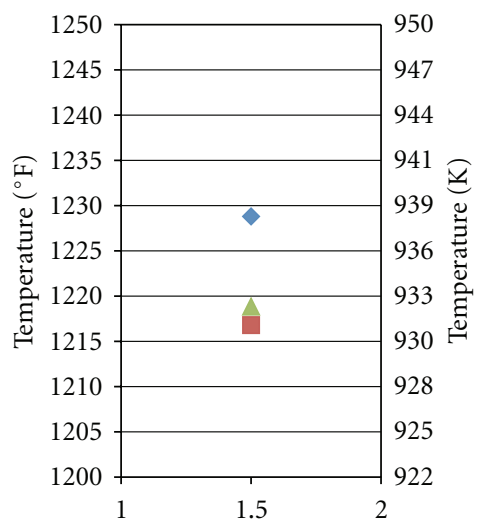

Normalized circumferential TC location $(\Theta)$

- Col O JP-8 0.015 in aft

- Col K FT 0.015 in aft

- Col M 50:50 0.015 in aft

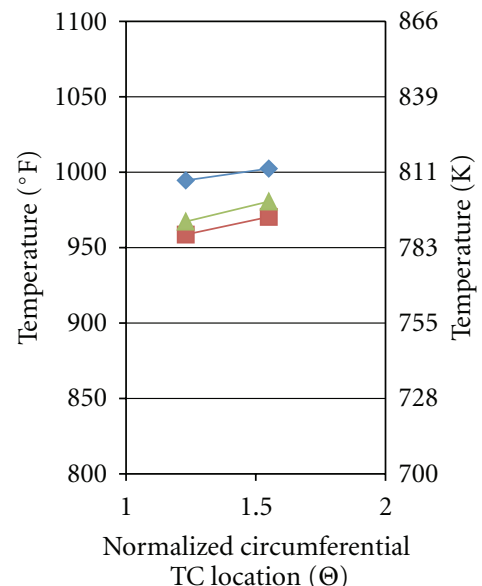

TC location $(\Theta)$

$\checkmark$ Col O JP-8 0.015 in forward

- Col K FT 0.015 in forward

- Col M 50:50 0.015 in forward

(d)

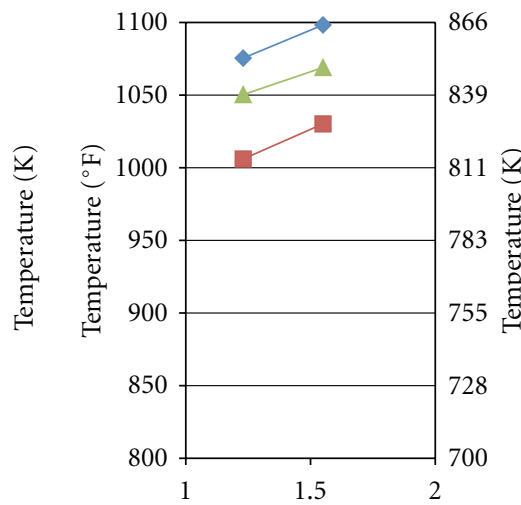

Normalized circumferential

TC location $(\Theta)$

- Col Q JP-8 0.02 in forward

Col V FT 0.02 in forward

- Col T 50:50 0.02 in forward

(e) continued

Figure 7: Continued. 


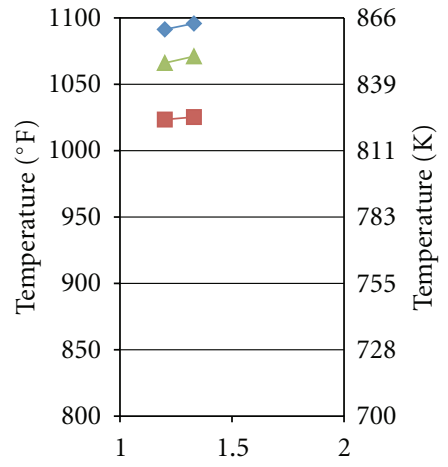

Normalized circumferential TC location $(\Theta)$

$\neg$ Col Q JP-8 0.02 in midplane

- Col V FT 0.02 in midplane

- Col T 50:50 0.02 in midplane
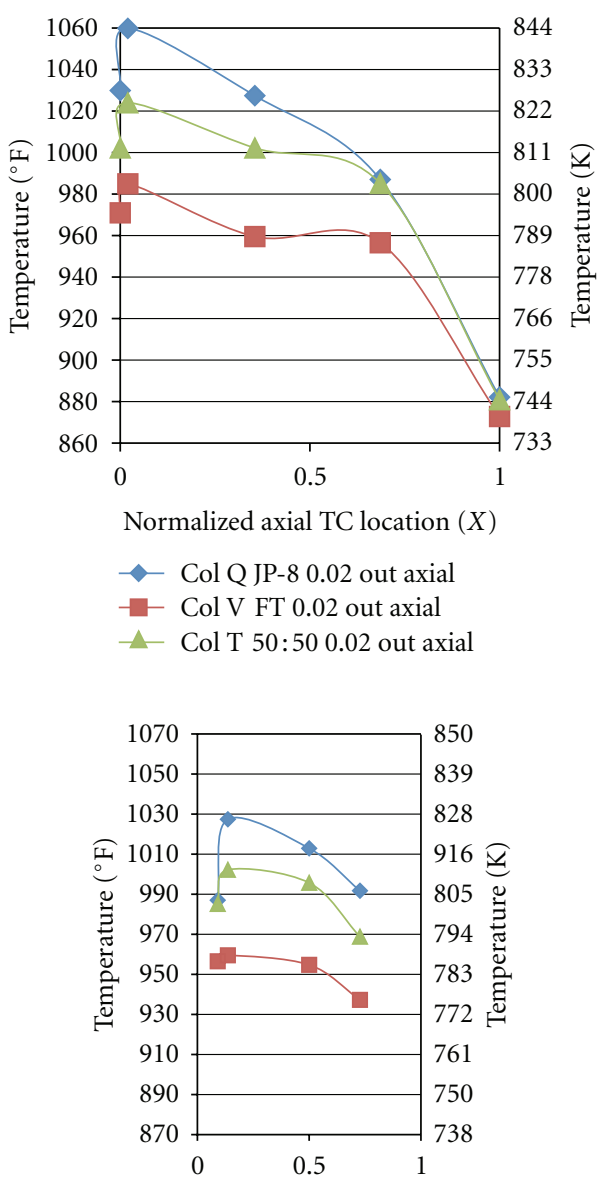

Normalized circumferential TC location $(\Theta)$

$\checkmark$ Col Q JP-8 0.02 out midplane

Col V FT 0.02 out midplane

- Col T 50:50 0.02 out midplane

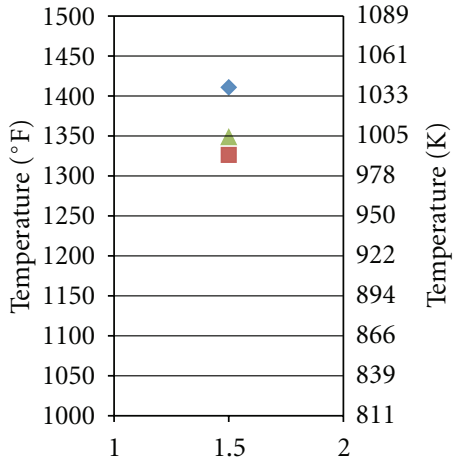

Normalized circumferential TC location $(\Theta)$

$\checkmark-$ Col Q JP-8 0.02 in aft

- Col V FT 0.02 in aft

$\triangle$ Col T 50:50 0.02 in aft

(e)

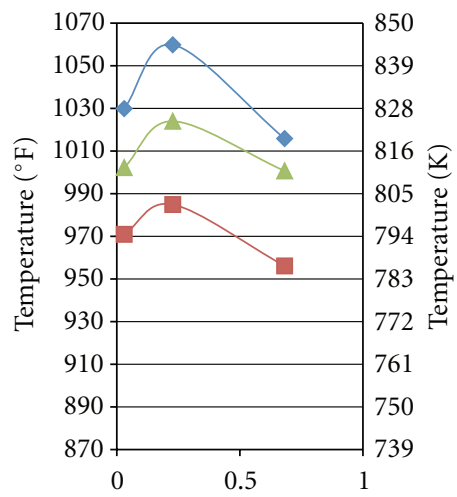

Normalized circumferential TC location $(\Theta)$

$\downarrow$ Col Q JP-8 0.02 out forward

- Col V FT 0.02 out forward

- Col T 50:50 0.02 out forward

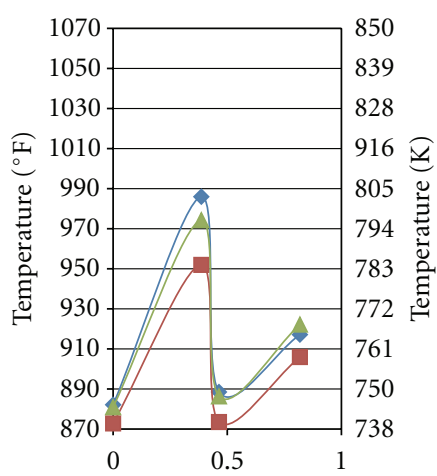

Normalized circumferential TC location $(\Theta)$

$\checkmark$ Col Q JP-8 0.02 out aft

- Col V FT 0.02 out aft

- Col T 50:50 0.02 out aft

(f)

Figure 7: (a) Combustor liner inner surface temperature variations with fueling composition at $F / A=0.010$. (b) Combustor liner outer surface temperature variations with fueling composition at $F / A=0.010$. (c) Combustor outer liner temperature variations with fueling composition at $F / A=0.015$. (d) Combustor inner liner temperature variations with fueling composition at $F / A=0.015$. (e) Combustor inner liner temperature variations with fueling composition at $F / A \sim 0.020$. (f) Combustor outer liner temperature variations with fueling composition at $F / A \sim 0.020$. 


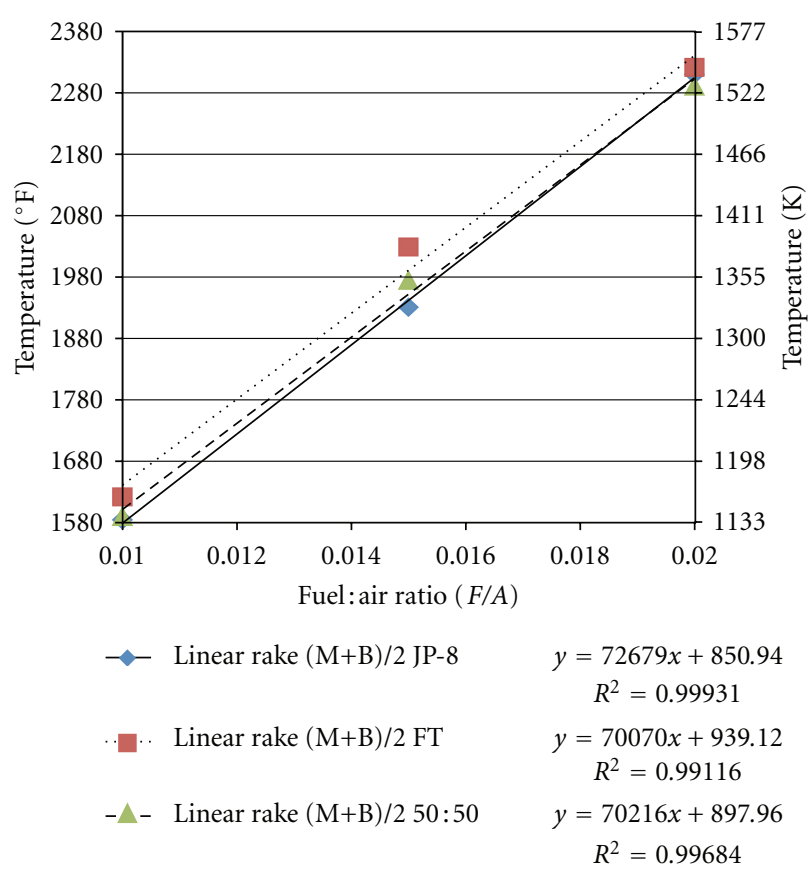

FIGURE 8: Variation of exhaust plume temperatures with percent fueling as a function of fuel : air ratio $(F / A)$.

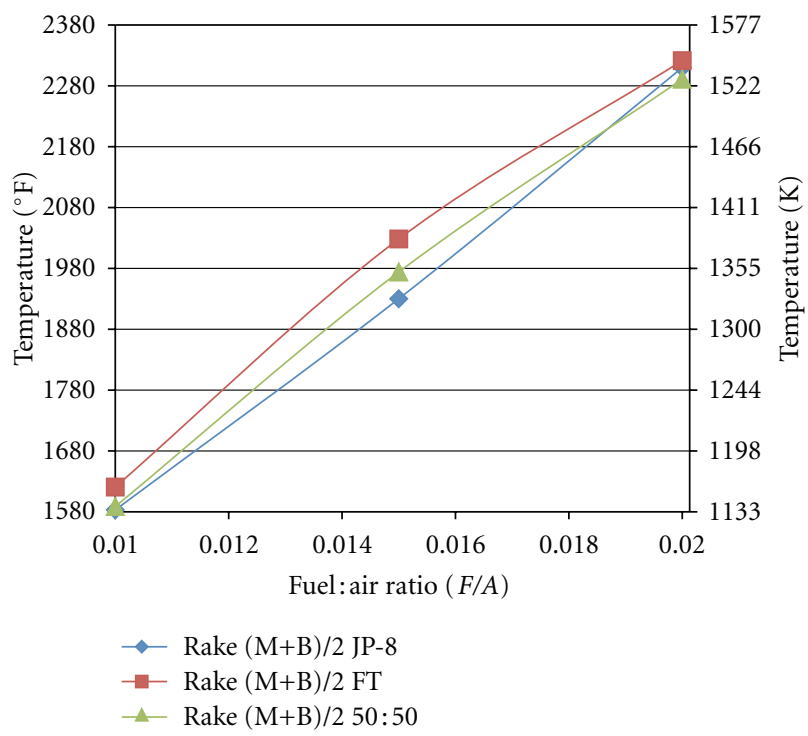

FIgURE 9: Curvature of exhaust plume temperature loci with percent fueling as a function of fuel : air ratio $(F / A)$.

to as the main fuel delivery system. The identical system was fed the alternative fuel supply, which is pumped from the trailer into the facility primary fuel system and ultimately blended online with the main fuel system to provide the desired fuel blend from $0 \%$ to $100 \%$ trailer fuel. An analysis of fuel blending errors is provided in Appendix C. To verify the 50/50 blend, samples were collected just upstream of the fuel injectors and analyzed using liquid chromatography; blending is within $\pm 4 \%$.
TABLE 1: Variations in combustor efficiencies with $F / A$ and fueling composition for nominal inlet conditions at $225 \mathrm{psia}(1.551 \mathrm{MPa})$

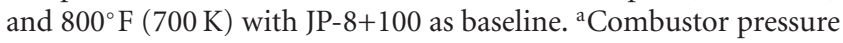
drop $\sim 3 \%$.

\begin{tabular}{|c|c|c|c|}
\hline$F / A$ & $\mathrm{JP}-8+100$ & JP-8: FT $50: 50$ blend & FT \\
\hline & F & $\mathrm{H}$ & G \\
\hline \multirow[t]{2}{*}{0.010} & 99.89 & 99.9 & 99.91 \\
\hline & $\mathrm{O}$ & $\mathrm{K}$ & $\mathrm{M}$ \\
\hline \multirow[t]{2}{*}{0.015} & 99.93 & 99.94 & 99.91 \\
\hline & $\mathrm{Q}$ & $\mathrm{U}$ & $\mathrm{T}$ \\
\hline 0.020 & 99.94 & 99.94 & 99.95 \\
\hline 0.025 & & & \\
\hline
\end{tabular}

2.2.2. Test Parameters and Data Collection. For this series of testing, the nominal test conditions for pressures and temperatures of blends and the extensive data collection systems have been established. The parameters were chosen to be most representative of engine operations envelope from idle to altitude cruise; however, TO (take-off) pressures are currently beyond the range of this facility.

\section{Combustor Parameters}

Inlet pressures $(P): 75,125,175$, and 225 psia $(0.517$, $0.862,1.207$, and $1.551 \mathrm{MPa}$ ).

Inlet temperature $(T): 500,625,725$, and $790^{\circ} \mathrm{F}(533$, 603, 658, and $694 \mathrm{~K})$.

Combustor pressure drops $(\Delta P): 3 \%, 4 \%$, and $5 \%$.

Fuel blends: 100\% JP-8, 50:50 JP-8:FT, and 100\% FT.

\section{Data Collection}

Gaseous emissions.

Exit temperature rake type B thermocouples, (also for metal and sidewall temperatures).

Photodiode output (voltage).

Still and high-speed photography.

Smoke and particulate emissions.

Combustor outer and inner liner temperature data are given in Appendix D, and estimates of errors in performance, flame temperature, emissions data, and geometric coordinates are given in Appendix C.

2.3. Combustor Thermal Performance. The combustion efficiencies for combinations of fuel: air ratio $F / A$ and fuel compositions were of the order of $99.9 \%$ (Table 1), and one is unable to distinguish combustor changes from this single parameter; thus, other parameters will be investigated. For example, the emission-based calculated flame temperature (Figure 2) increases with $F / A$, with FT about $\Delta T=70^{\circ} \mathrm{F}$ 

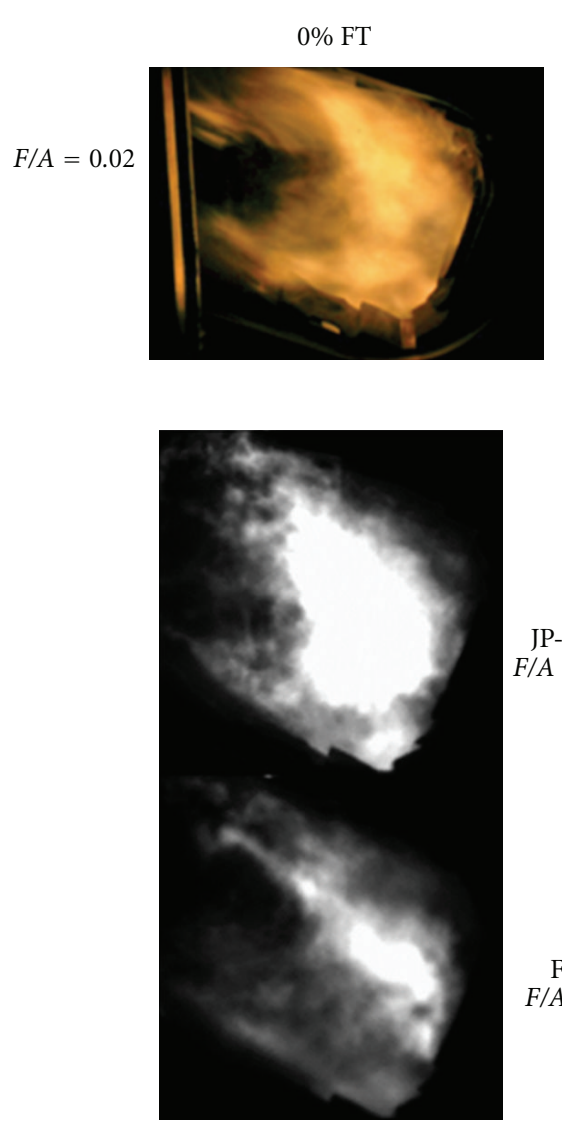

50\% FT: $50 \%$ JP-8

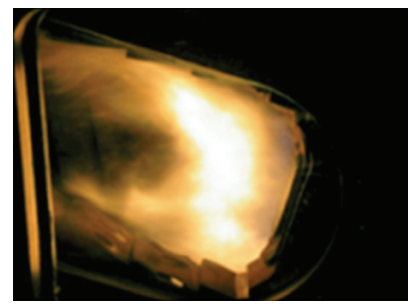

(a)
JP-8 fuel
$F / A=0.015$
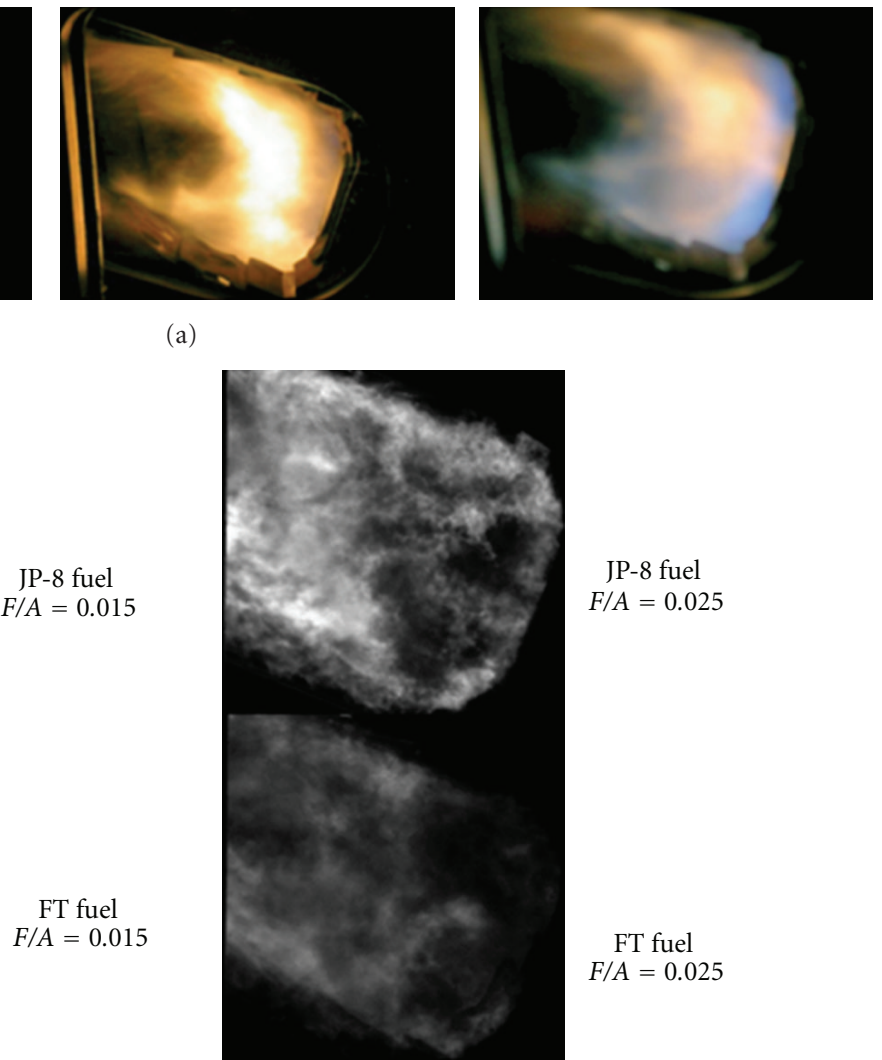

(b)

Figure 10: Combustor A experiment photographs illustrating changes in flame structure with changes in fuel blend. (a) Digital camera photographs illustrating changes in flame structure with changes in fuel blend at $F / A=0.020$. (b) High-speed video sequences comparing JP-8+100 fueling to FT fueling combustion at two different fuel : air ratios $(F / A)$.

$(39 \mathrm{~K})$ higher. This will be discussed further in the next section.

Lean blow out (LBO) and ignition (IGN) tests were not part of the planned test program, yet observations made during startup and shutdown procedures were consistent with previous JP- $8+100$ testing. For a limited data set at a nominal $5 \%$ combustor pressure drop, LBO is nearly $40 \%$ of the (IGN) $F / A$ for both $100 \%$ FT and JP- $8+100$. The average LBO $F / A$ values are

$$
\begin{gathered}
\mathrm{LBO}_{100 \% \mathrm{FT}}=0.0038 \pm 0.0004 \\
\mathrm{LBO}_{\text {JP- } 8+100}=0.0043 \pm 0.0004 \\
\frac{(F / A)_{\text {LBO } 100 \% \mathrm{FT}}}{(F / A)_{\mathrm{LBO} J P-8+100}}<1
\end{gathered}
$$

with some sensitivity to percent combustor pressure drop. The average ignition $F / A$ values are

$$
\begin{gathered}
\mathrm{IGN}_{100 \% \mathrm{FT}}=0.010 \pm 0.004, \\
\mathrm{IGN}_{\mathrm{JP}-8+100}=0.013 \pm 0.007, \\
\frac{(F / A)_{\text {IGN } 100 \% \mathrm{FT}}}{(F / A)_{\text {IGN JP- } 8+100}}<1 .
\end{gathered}
$$

No further tests were undertaken, and data at lower combustor pressure drops were insufficient to be definitive. Systematic altitude restart, ignition, and LBO studies are yet to be conducted.

2.4. Surface Thermal Measurements. The combustor walls and liners were instrumented for pressure and temperature. In general the pressure drop measurements are sensitive information and will not be presented as such. It should be noted that no inconsistent pressure measurements were found.

The liner and wall surface temperature locations are sensitive information, and temperatures are noted as sidewall or liner (i.e., facing inside or outside).

For all figures herein, fuel compositions are denoted as follows: JP-8+100 is JP-8, Fischer-Tropsch is FT, and blended $50 \% \mathrm{JP}-8+100$ and $50 \%$ FT by volume is $50: 50$.

2.4.1. Sidewalls. Figure 3 illustrates that sidewall temperatures (TSW) strongly depend on F/A and weakly depend on fuel blend composition JP-8, FT, and 50:50. FWD represents forward; MID midplane; AFT the aft axial position of the thermocouple. 


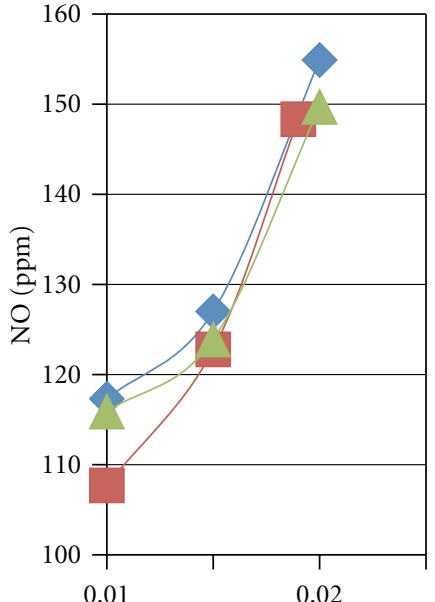

Fuel: air ratio $(F / A)$

- NOppm JP-8
- NOppm FT

- NOppm FT
- NOppm 50:50

(a)

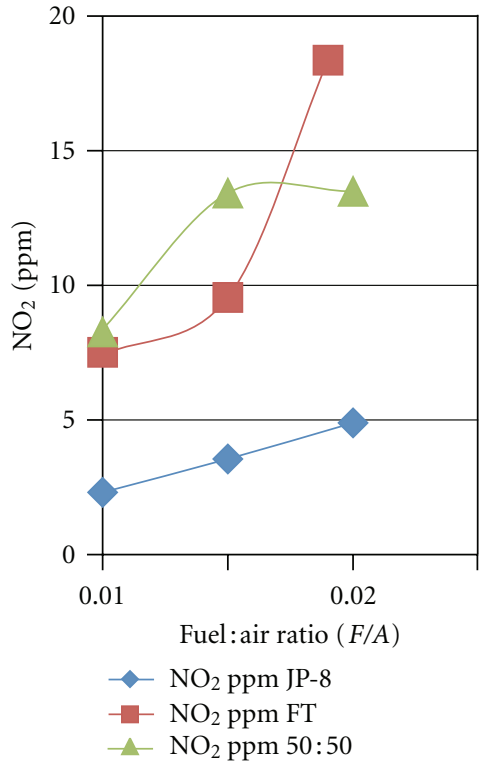

(b)

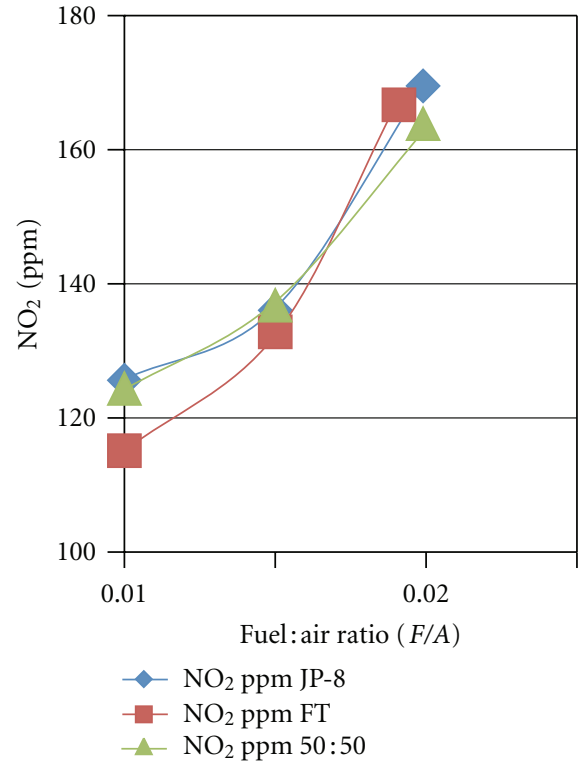

(c)

Figure 11: (a) Nitric oxide emission (ppm) variations with $F / A$ and fueling composition. (b) Nitrogen dioxide emission (ppm) variations with $F / A$ and fueling composition. (c) $\mathrm{NO}_{x}$ emission variations $(\mathrm{ppm})$ with $F / A$ and fueling composition. $\left[(\mathrm{g} / \mathrm{kg})\left[\mathrm{EINO}_{x}\right.\right.$ or $\left.\mathrm{KHNO}_{x}\right] \approx$ $\left.\left.(\mathrm{ppm} \mathrm{NO})_{x}\right)(1+\mathrm{FAR}) /(630 \mathrm{FAR})\right]$. FAR: fuel : air ratio $F / A[1] .\left[(\mathrm{g} / \mathrm{kg})\left[\mathrm{EINO}_{x}\right.\right.$ or $\left.\left.\mathrm{KHNO}_{x}\right] \approx(\mathrm{ppm} \mathrm{NO} x)(1+\mathrm{FAR}) /(715 \mathrm{FAR})\right] . \mathrm{FAR}$ : fuel : air ratio $F / A$ (herein, arp). $\left[(\mathrm{g} / \mathrm{kg})\left[\mathrm{EINO}_{x}\right.\right.$ or $\left.\left.\mathrm{KHNO}_{x}\right] \approx(\mathrm{ppm} \mathrm{NO} x)(1+\mathrm{FAR}) /(655 \mathrm{FAR})\right]$. FAR: fuel : air ratio $F / A($ herein, arpc). Aerospace-recommended practice $(\operatorname{arp})$ and $(\operatorname{arpc})$ corrected arp. $\mathrm{EI}_{Z} \approx\left[10^{3} m_{Z} / m_{f}\right] \times\left[m_{f}\left(1+\mathrm{FAR}^{-1}\right) / m_{\text {gas products }}\right] \times\left[\mathrm{mol}_{Z} M_{Z} / m_{Z}\right] \times$ $\left[m_{\text {gas products }} /\left(\sum \mathrm{mol}_{j} \mathrm{M}_{j}\right)_{\text {gas products }}\right] \times 10^{3} / 10^{3} \times 10^{-6} \mathrm{ppm} . m_{X}$ : mass flow rate of $X(\mathrm{~g} / \mathrm{s}), m_{f}$ : mass flow rate of fuel $(\mathrm{kg} / \mathrm{s}), M_{X}: \mathrm{molar}$ mass of $X$, $\operatorname{mol}_{X}$ : moles of $X$, and FAR: fuel : air ratio F/A. (g/kg) $\left[\mathrm{EINO}_{x}\right]$ SAE ARP $1533 \sim\left\{\left[\mathrm{NO}_{x}\right] /\left([\mathrm{CO}]+\left[\mathrm{CO}_{2}\right]+\left[\mathrm{C}_{x} \mathrm{H}_{y}\right]\right\} \times 10^{3} M_{\mathrm{NO}_{x}} /\left(M_{\mathrm{C}}+\alpha M_{\mathrm{H}}\right)\right.$. $\left[\mathrm{NO}_{x}\right][\mathrm{CO}]\left[\mathrm{CO}_{2}\right]\left[\mathrm{C}_{x} \mathrm{H}_{y}\right]=$ mass fractions of $\mathrm{NO}_{x}, \mathrm{CO}, \mathrm{CO}_{2}$, and total hydrocarbon THC, $M:$ molar mass, $\alpha$ : ratio of $\mathrm{H} / \mathrm{C}: n / m$ in fuel $\mathrm{C}_{m} \mathrm{H}_{n}$ where $\mathrm{NO}_{x}$ mol mass is assumed to be 46, contrast to Figures 11(a) and 11(b).

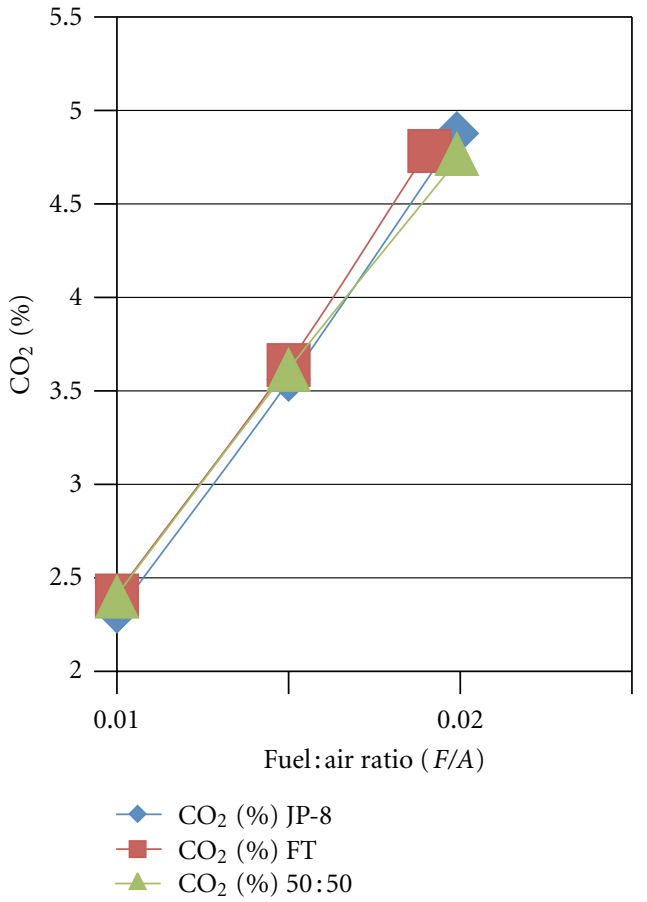

FIGURE 12: Variation of $\% \mathrm{CO}_{2}$ with $F / A$ and fuel composition.

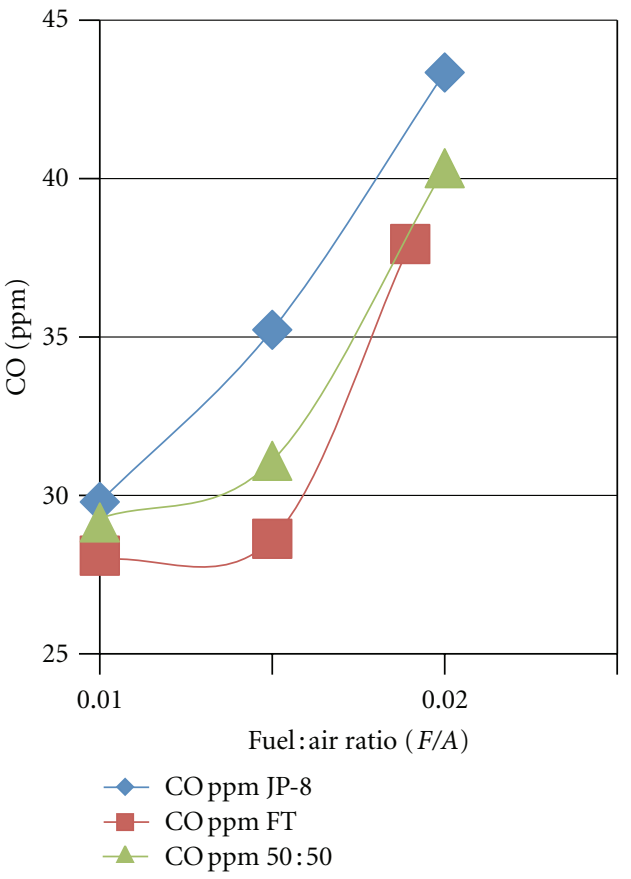

FIGURE 13: Variation of $\mathrm{CO}$ (ppm) with $F / A$ and fuel composition. $[(\mathrm{g} / \mathrm{kg}) \mathrm{EICO} \approx(\mathrm{ppm} \mathrm{CO})(1+\mathrm{FAR}) /(1220 \mathrm{FAR})]$. FAR: fuel : air ratio $F / A$. 


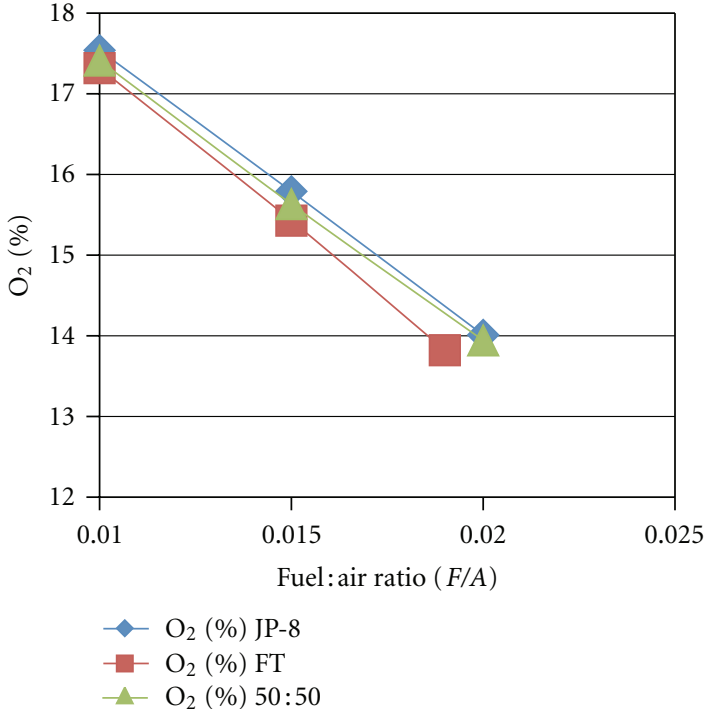

Figure 14: Variation of $\% \mathrm{O}_{2}$ with $F / A$ and fuel composition.

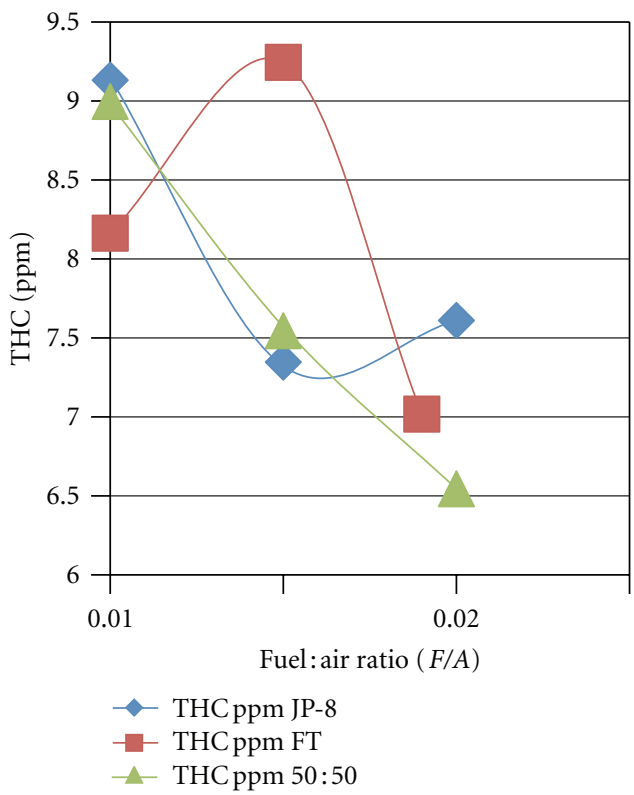

FIgure 15: Total hydrocarbon variations, THC (ppm) with $F / A$ and fuel composition. [ $(\mathrm{g} / \mathrm{kg}) \mathrm{THC} \approx(\mathrm{ppm}$ THC) $(1+\mathrm{FAR}) /$ (2070 FAR)]. FAR: fuel : air ratio $F / A$.

2.4.2. Unwrapped Combustor Liner. Figures 4(a), 4(b), and 4 (c) represent unwrapped liner surface temperatures for three $F / A$ values $(0.010,0.015$, and 0.020$)$ and three fueling compositions (JP-8, FT, and 50:50). The twin peaks represent sidewall (largest) and maximum inner liner temperatures, respectively. Temperature differences baselined to JP- $8+100$ are provided in Appendix B. We use the term "unwrapped" to mean the normalized outside liner surface circumference ( 0 to 1 ) to normalized inner liner circumferential surface ( 1 to 2 ) as a "continuous loop."

Figure 4(a) illustrates the unwrapped liner temperatures for $F / A=0.010$ with outer liner temperatures to the left of

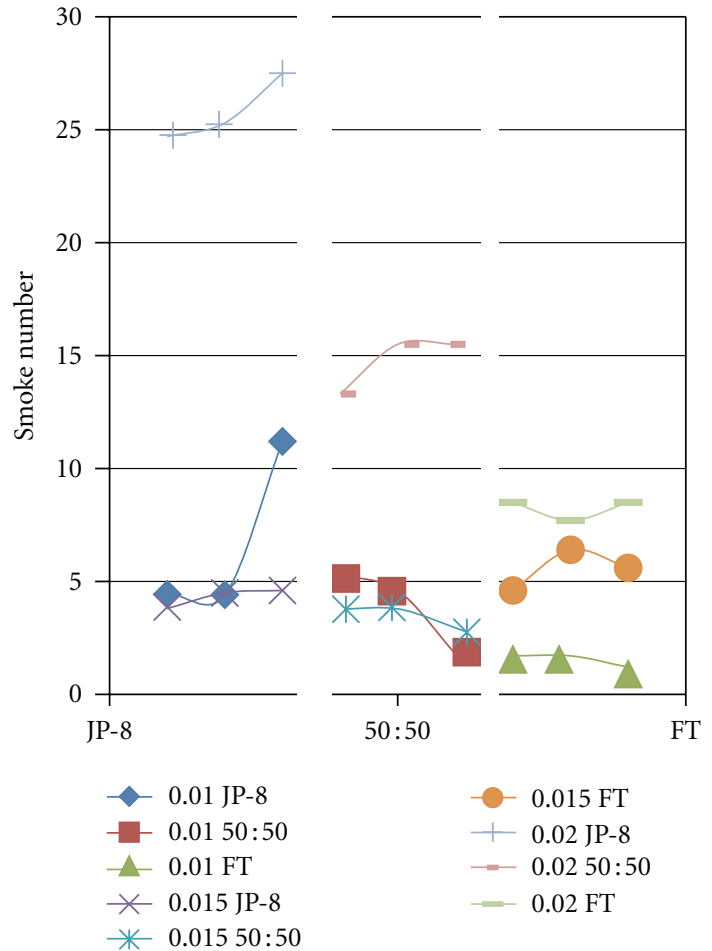

FIGURE 16: Smoke number variations with $F / A$ and fueling composition.

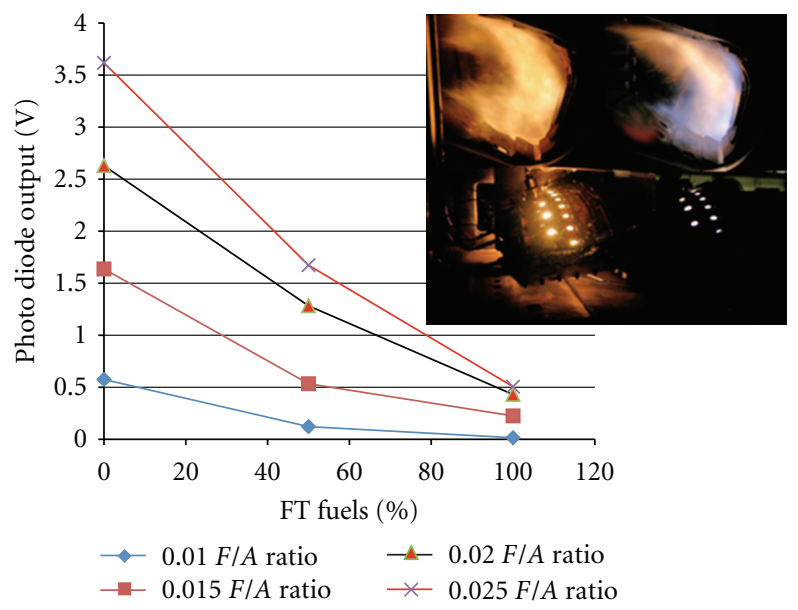

FIGURE 17: Variation in photodiode voltage output with fuel blending at various F/A values for $100 \%$ JP-8 and 100\% FT fueling as well as $50 \%$ blend of JP- 8 and FT fuel; $(P, T)_{\text {inlet }}$ is [75 psia $\left.(0.517 \mathrm{MPa}), 500^{\circ} \mathrm{F}(533 \mathrm{~K})\right]$ at $3 \%$ combustor pressure drop. Photo on left are $100 \%$ JP-8 and on the right $100 \% \mathrm{FT}$ at $F / A=0.010$. Upper photos are of combustor flame, lower of combustor liner.

the peak and inner liner temperatures to the right of the peak. The temperatures are slightly higher for the FT fueling.

Figure 4(b) represents unwrapped liner temperatures for $F / A=0.015$ with outer liner temperatures to the left of the peak and inner liner temperatures to the right of the peak. The temperatures are lower for the FT fueling. 


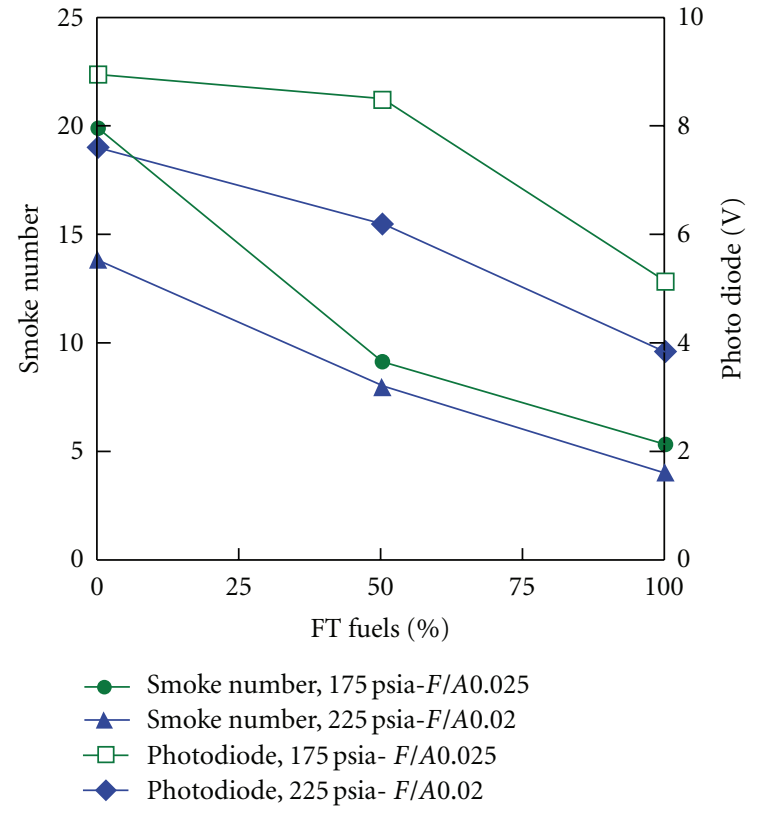

FIGURE 18: Smoke number variations with \% FT fueling for combustor inlet pressures of 175 and $225 \mathrm{psia}$ (1.207 and $1.551 \mathrm{MPa}$ ) at $F / A=0.020$ and 0.025 . Results imply reductions in polycyclic aromatic hydrocarbons (PAH) (soot) and polycyclic aromatic compounds (PAC). [Note: FT fuels have few if any aromatics and lower total particulates].

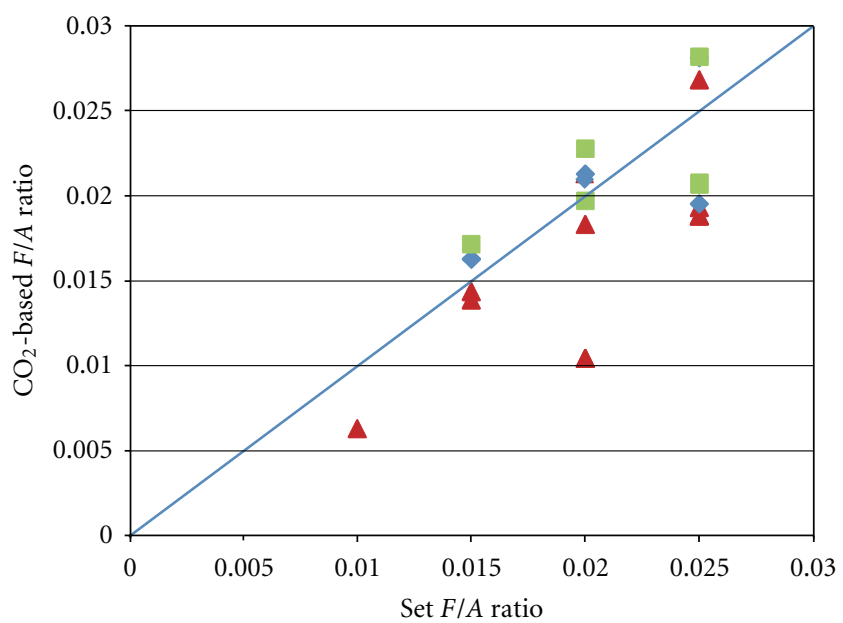
$\triangle \mathrm{JP}-8$
$\checkmark$ FT blend
FT

FIgURE 19: Alternate fuel experimentally set $F / A$ versus $\mathrm{CO}_{2}$-based calculated $F / A$.

Figure 4(c) represents the unwrapped liner temperatures for $F / A=0.020(\mathrm{JP}-8)$ and 0.019 (FT) with outer liner temperatures to the left of the peak and inner liner temperatures to the right of the peak. The temperatures are lower for the FT fueling.

Figures 5(a), 5(b), and 5(c) represent unwrapped liner surface temperatures differences relative to JP-8+100 as

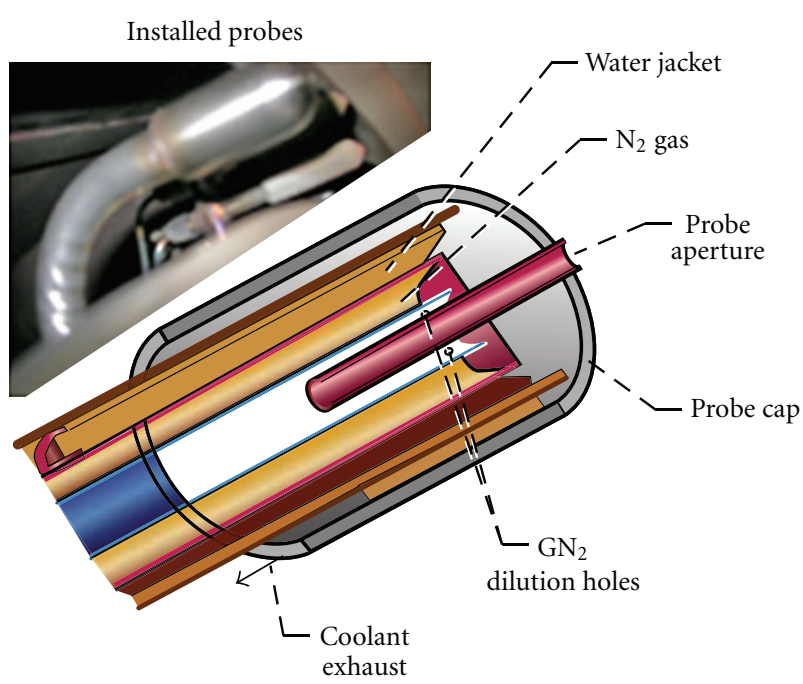

Figure 20: Emissions probes installed at combustor exhaust exit plane. Particulate probe is in photo foreground with gas emissions/TC rake probes in background. Details of the water cooled, nitrogen gas dilution particulate probe shown in inset. Probe cap outer diameter $=0.075$ in $(19 \mathrm{~mm})$ with aperture diameter 0.044 in $(1.12 \mathrm{~mm})$. Both diluted and undiluted probes were installed. Photo of installed probes shown rotated out of true combustor exhaust plane position.

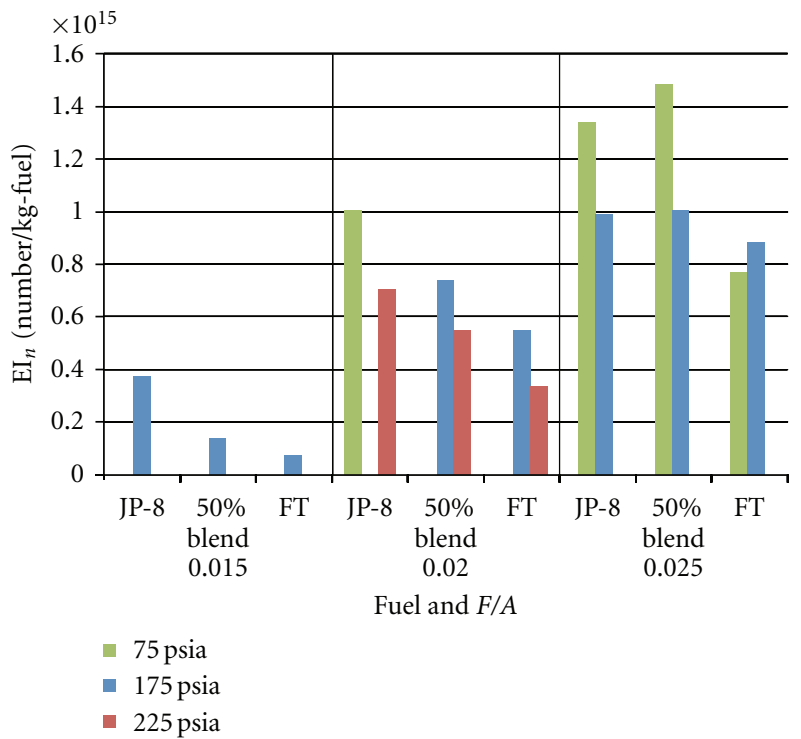

FIgUre 21: Particulate emissions number indices variations with test pressure and $F / A$ for JP-8, FT blend, and FT fueling. [Note: test data set incomplete at 75 psia and 225 psia for $F / A=0.015$ and at 225 psia for $F / A=0.025$ ].

baseline, for three $F / A$ values $(0.010,0.015$, and 0.020$)$ and three fueling compositions (JP-8, FT, and 50:50).

Figure 5(a) represents the unwrapped liner differences $\left[T_{\text {fuel blend }}-T_{\text {JP- } 8}\right]$ for $F / A=0.010$ and fueling compositions $50: 50$ and FT. Normalized combustor liner thermocouple locations 0 to 1 outer and 1 to 2 inner. JP-8 difference is 0 . On average, the unwrapped liner temperatures are nominally 


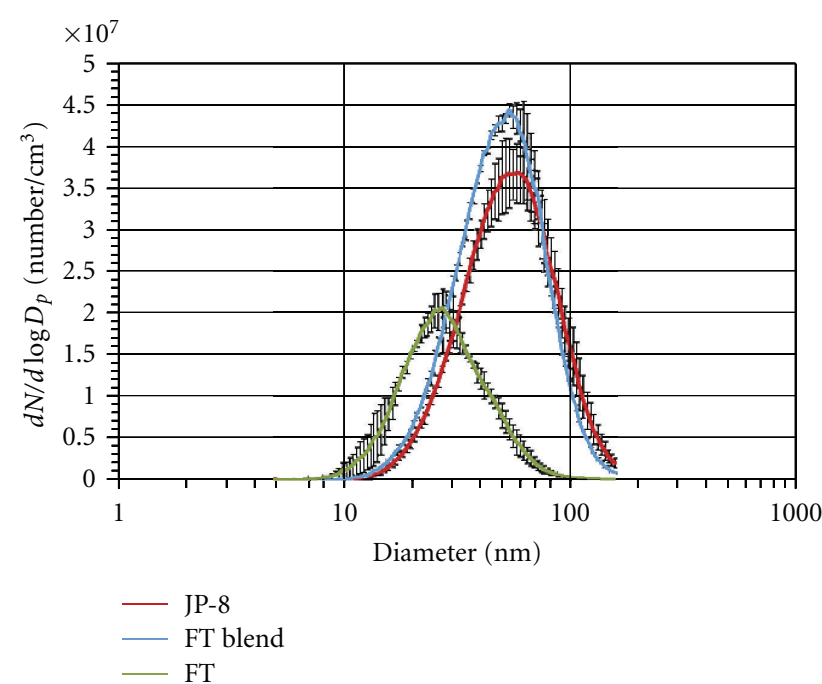

FIGURE 22: Alternate fueling particle size distribution with JP-8, FT blend, and FT for combustor pressure at 75 psia $(0.517 \mathrm{MPa})$ and $F / A=0.025 . d \mathrm{EI} / d\left(\log D_{p}\right)=2.833 \times 10^{3}\left[d N / d\left(\log D_{p}\right)\right][(1+$ FAR)/FAR $](T / P)$, where $N=$ number $/ \mathrm{cm}^{3}, \mathrm{EI}=$ number $/ \mathrm{kg}$, and $\mathrm{FAR}=$ fuel : air ratio $F / A ; P$ is instrument pressure in atmospheres and $T$ is temperature in $\mathrm{K}$ (herein $1 \mathrm{~atm}$ and $\sim 293 \mathrm{~K}$ ).

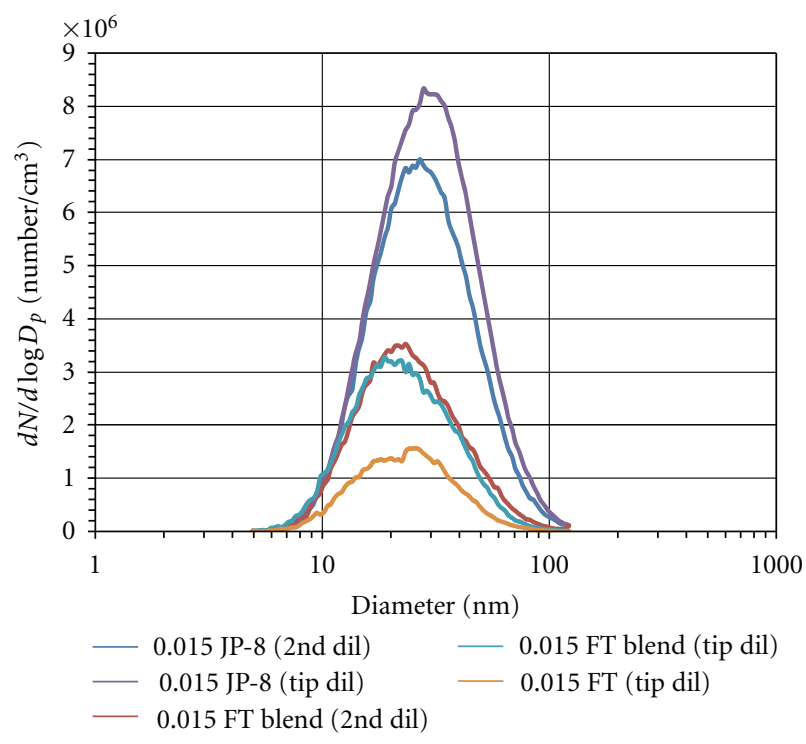

Figure 23: Particulate size distribution changes with probe dilution with JP-8, FT blend, and FT fuels for combustor pressure 125 psia $(0.862 \mathrm{MPa})$ and $F / A=0.015 . d \mathrm{EI} / d\left(\log D_{p}\right)=2.833 \times$ $10^{3}\left[d N / d\left(\log D_{p}\right)\right][(1+\mathrm{FAR}) / \mathrm{FAR}](T / P)$, where $N=$ number $/ \mathrm{cm}^{3}$, $\mathrm{EI}=$ number $/ \mathrm{kg}$, and $\mathrm{FAR}=$ fuel $:$ air ratio $F / A ; P$ is instrument pressure in atmospheres and $T$ is temperature in $\mathrm{K}$ (herein $1 \mathrm{~atm}$ and $\sim 293 \mathrm{~K})$.

$10^{\circ} \mathrm{F}\left(6^{\circ} \mathrm{C}\right)$ higher for FT and blended fueling than for JP-8 fueling, with actual differences given in Appendix B.

Figure 5(b) represents the unwrapped liner differences $\left[T_{\text {fuel blend }}-T_{\mathrm{JP}-8}\right]$ for $F / A=0.015$ and fueling compositions JP-8 and FT. Normalized combustor liner thermocouple locations 0 to 1 outer and 1 to 2 inner. JP- 8 difference is 0 . On

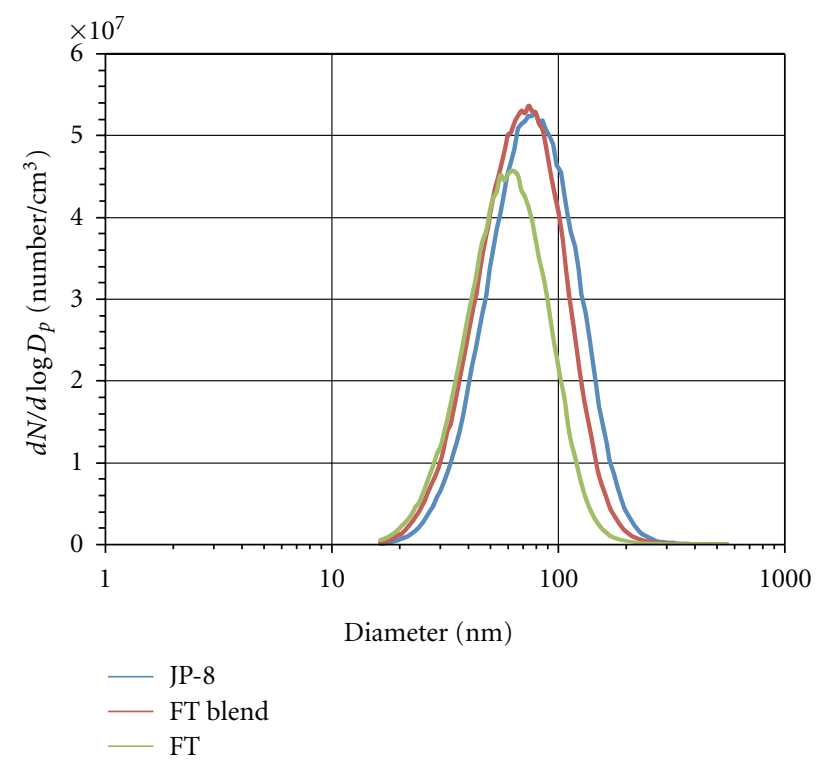

Figure 24: Particle size distribution with JP-8, FT blend, and FT for combustor pressure $175 \mathrm{psia}(1.207 \mathrm{MPa})$ and $F / A=0.025$. $d \mathrm{EI} / d\left(\log D_{p}\right)=2.833 \times 10^{3}\left[d N / d\left(\log D_{p}\right)\right][(1+\mathrm{FAR}) / \mathrm{FAR}](T / P)$ where $N=$ number $/ \mathrm{cm}^{3}, \mathrm{EI}=$ number $/ \mathrm{kg}$, and $\mathrm{FAR}=$ fuel : air ratio $\mathrm{F} / \mathrm{A} ; \mathrm{P}$ is instrument pressure in atmospheres and $T$ is temperature in $\mathrm{K}$ (herein $1 \mathrm{~atm}$ and $\sim 293 \mathrm{~K}$ ).

average, compared with JP- $8+100$ fueling, the unwrapped liner temperatures are nominally $20^{\circ} \mathrm{F}\left(11^{\circ} \mathrm{C}\right)$ lower for FT fueling and $14^{\circ} \mathrm{F}\left(8^{\circ} \mathrm{C}\right)$ lower for $50: 50$ blended fueling; actual differences are given in Appendix B.

Figure 5(c) represents the unwrapped liner temperatures differences $\left[T_{\text {fuel blend }}-T_{\mathrm{JP}-8}\right]\left({ }^{\circ} \mathrm{F}\right)$ for $F / A \sim 0.020$ and fueling compositions $50: 50$ and FT. Normalized combustor liner thermocouple locations 0 to 1 outer and 1 to 2 inner. JP-8 difference is 0 . On average, compared with JP-8+100 fueling, the unwrapped liner temperatures are nominally $45^{\circ} \mathrm{F}\left(25^{\circ} \mathrm{C}\right)$ lower for FT fueling and $18^{\circ} \mathrm{F}\left(10^{\circ} \mathrm{C}\right)$ lower for blended fueling; see differences given in Appendix B.

Figure 6 shows that peak inner liner temperatures are nearly independent of fueling composition from $100 \%$ JP-8 to $100 \%$ FT.

2.4.3. Combustor Inner and Outer Liner. Eliminating the sidewall peak temperature allows the visualization of the smaller changes in surface temperatures. Omitting the peak temperature, Figures $7(\mathrm{a})-7(\mathrm{f})$ illustrate major portions of the combustor liner axial and circumferential surface temperature variations with $F / A$ and fueling composition. Throughout, the individual data points are connected by continuous curves for ease of comparison, not to imply that the authors know or understand the physical processes occurring between data points.

Figures 7(a) and 7(b) illustrate variations of combustor axial and circumferential surface temperatures with temperature differences baselined to JP-8+100 in Appendix B, with distribution illustrated in Figures 5(a), 5(b), and 5(c). Figure 7(a) shows inner liner temperatures at $F / A=0.010$ 


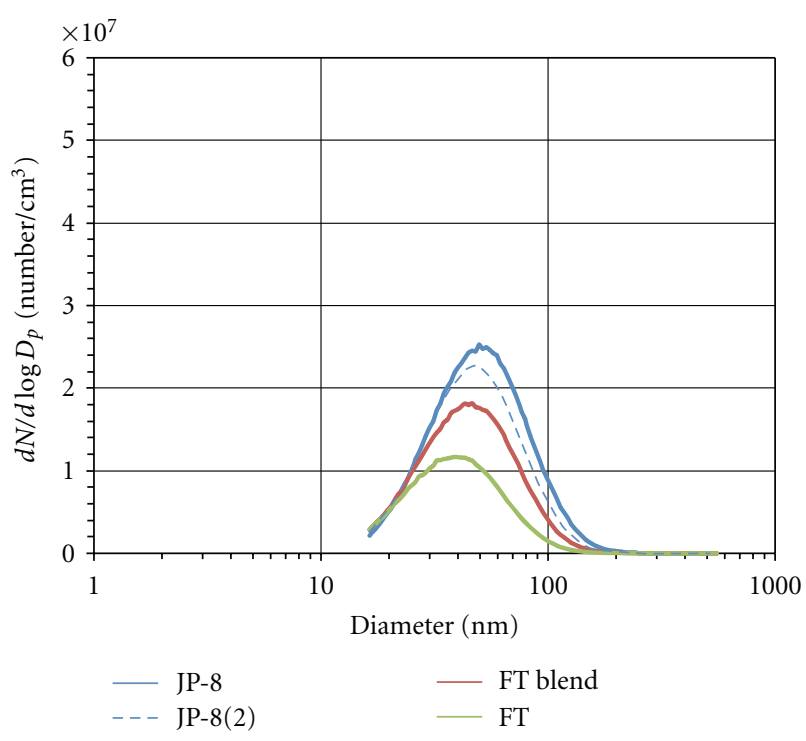

Figure 25: Particulate size distribution for JP-8, FT blend, and FT fueling at combustor pressure $225 \mathrm{psia}(1.551 \mathrm{MPa})$ and $F / A=0.020 . d \mathrm{EI} / d\left(\log D_{p}\right)=2.833 \times 10^{3}\left[d N / d\left(\log D_{p}\right)\right][(1+$ FAR $) / F A R](T / P)$, where $N=$ number $/ \mathrm{cm}^{3}, \mathrm{EI}=$ number $/ \mathrm{kg}$, and $\mathrm{FAR}=$ fuel : air ratio $F / A ; P$ is instrument pressure in atmospheres, and $T$ is temperature in $\mathrm{K}$ (herein $1 \mathrm{~atm}$ and $\sim 293 \mathrm{~K}$ ).

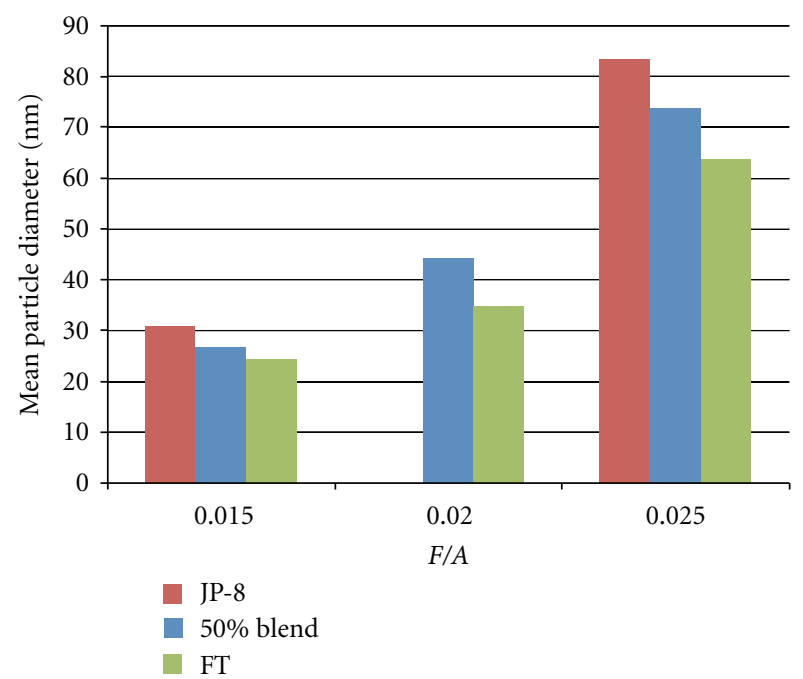

FIgure 26: Mean particle diameter with JP-8, FT blend, and FT fueling for combustor pressure $175 \mathrm{psia}(1.207 \mathrm{MPa})$ and $F / A$ values of $0.015,0.020$, and 0.025 .

for fueling composition changes from JP-8 to FT. The temperatures for FT and blended fueling are slightly higher than for JP-8 fueling. Figure 7(b) shows variations of outer liner combustions temperatures at $F / A=0.010$ for fueling composition changes from JP-8 to FT. The temperatures for FT and blended fueling are slightly higher than for JP-8 fueling.

Figure 7(c) shows variations of combustor outer liner temperatures at $F / A=0.015$ for fueling composition changes from JP-8 to FT. Figure 7(d) illustrates variations of combustor inner liner temperatures at $F / A=0.015$ for fueling composition changes from JP-8 to FT.

Figure 7(e) shows variations of combustor inner liner temperatures at $F / A \sim 0.020$ for fueling composition changes from JP-8 to FT. Figure 7(f) shows variations of combustor outer liner temperatures at $F / A \sim 0.020$ for fueling composition changes from JP-8 to FT.

2.5. Combustion Exhaust Rake Temperature. In the combustor thermal performance section, we noted that the SPKFT-calculated temperature based on emissions was higher than that of JP-8+100 (Figure 2). We now look at measured temperatures in the exhaust plane.

Three type- $B$ metal thermocouples formed a thermal rake, (top (T), midplane (M), and bottom (B)) to monitor the combustor exhaust. The top thermocouple was damaged by the exhaust plume after an initial set of test runs, restricting interpretation of exit plane temperatures, yet enough data were gathered prior to its loss to corroborate trends based solely on the average of $\mathrm{M}$ and $\mathrm{B}$ readings. The exhaust plume was hotter at the top than the bottom which affects the turbine inlet pattern factor. Herein, temperature $(\mathrm{T})>$ temperature $(\mathrm{M})>$ temperature $(\mathrm{B})$ with consistent trends for percent fueling as function of $F / A$, Figure 8. While dangerous to draw hard conclusions from sparse data sets, the trends are instructive. The linear locus fit to the SPK-FT and JP- $8+100$ data shows the SPK-FT exhaust temperature to be significantly higher than for JP$8+100$. With nearly equivalent slopes, the intercepts differ close to $88^{\circ} \mathrm{F}\left(49^{\circ} \mathrm{C}\right)$, which is higher but in reasonable agreement with the calculated flame temperature (Figure 2), based on emissions. The significance is twofold: (1) higher turbine inlet temperatures provide higher engine efficiencies, and (2) component life decreases. Pattern factors are very important to turbine efficiency, and component life can vary as much as $25 \%$ with a $10^{\circ} \mathrm{C}$ change in temperature. The third dangerous part of having sparse data is making assumptions about the trending. Figure 9 shows both the FT and 50:50 loci to be convex, whereas the JP-8+100 locus is concave with a potential optimum near $F / A=0.015$, implying crossover points. Drawing implications outside the $0.01 \leq F / A<0.02$ data set is not only unwarranted but dangerous.

2.6. Combustion Visualization. Digital camera exposures and high-speed photographs of the combustion process provide some insights for computational fluid dynamics (CFDs) analysts [5] as well as heuristic information for combustor designers, for example, luminosity variation with FT versus JP-8 concentration as illustrated in Figure 10(a), the digital camera pictures for $F / A=0.020$. The general trend is increased luminosity with increased percent JP-8+100 and F/A.

High-speed video at $20 \mathrm{kfps}$ illustrates the nature of the unsteady combustion processes (Figure 10(b) shows sequences from that video). The upper frames relate to JP-8+100 fueling ( $0 \% \mathrm{FT})$, and the lower frames relate to $100 \%$ FT fueling at two different fuel : air ratios $(F / A)$. Both 


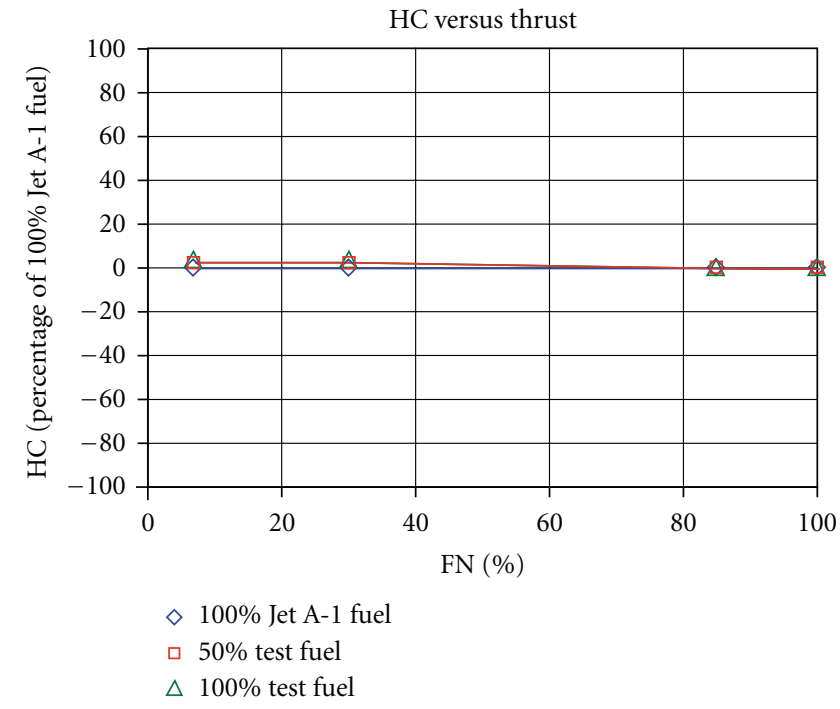

(a)

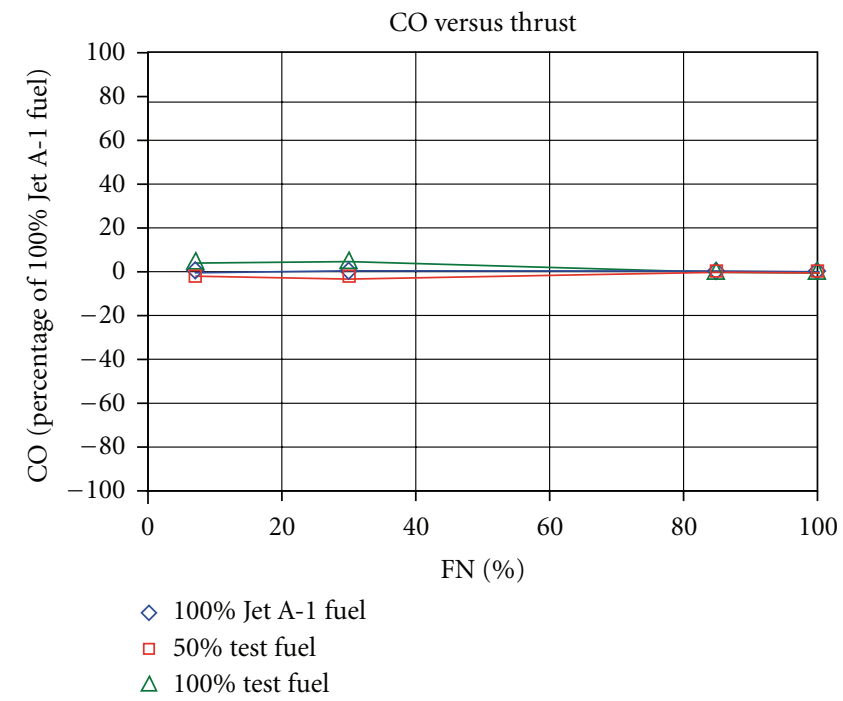

(c)

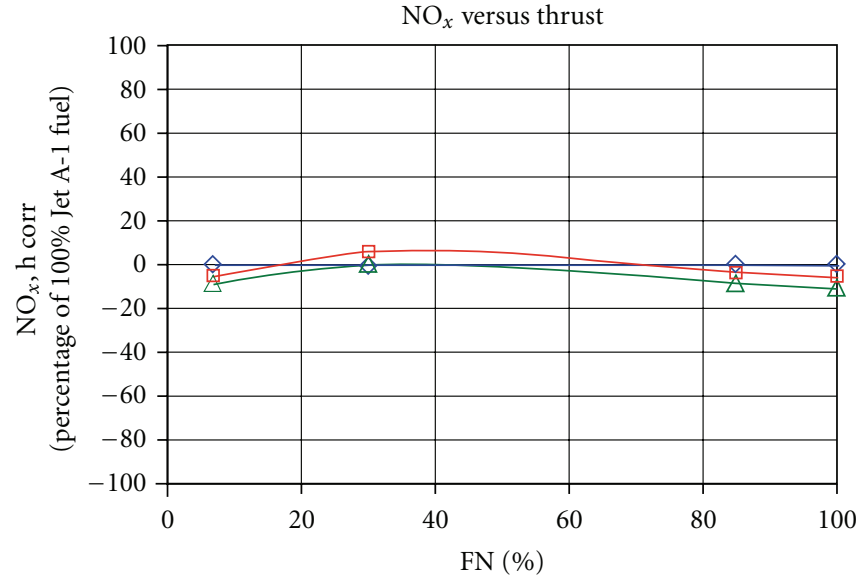

$\diamond 100 \%$ Jet A-1 fuel

$50 \%$ test fuel

$\triangle 100 \%$ test fuel

(b)

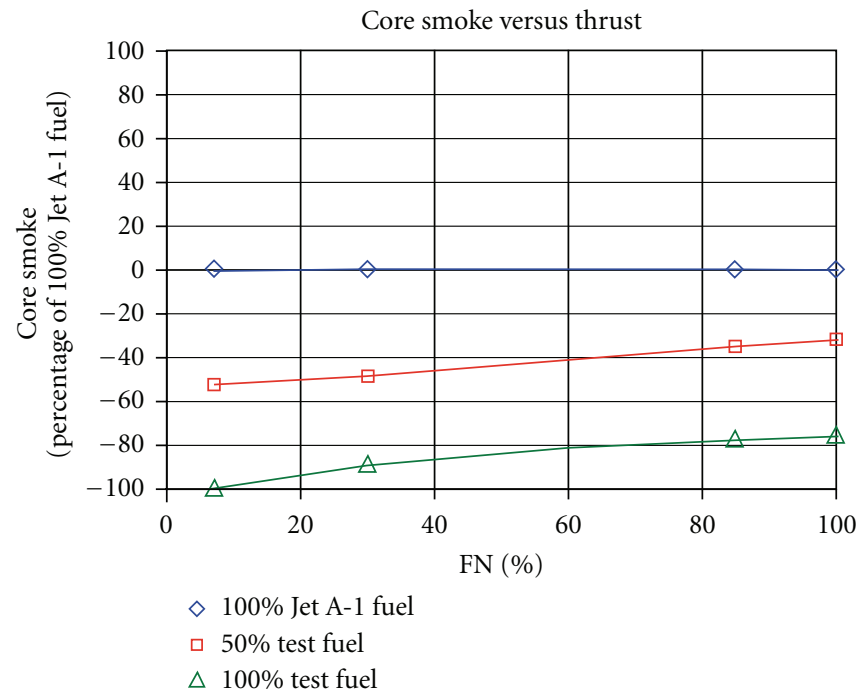

(d)

FIGURE 27: Small turbine engine emissions test results [2].

emissions and exit-plane thermocouple rake measurements indicate that FT fuels have higher heating values than JP$8+100$, producing higher calculated and measured flame temperatures at the combustor exit, yet with lower liner temperatures. These observations are backed up qualitatively by observation of flame luminosity using a photodiode as well as pictures and high-speed video movies providing visual observations.

2.7. Conclusions: Part A. Alternate fueling testing is being carried out to determine preliminary performance, emissions, and particulates combustor sector data for SPK-type (e.g., Fischer-Tropsch) fuel blends, relative to JP- $8+100$ as baseline fueling, and to make projections for testing biofuel fuel blends leading to preliminary development of smart fueling (fuel flexible) and combustor systems for the next generation aeronautic and aeronautic-derivative gas turbine engines. Herein alternate fueling test results for a wellcharacterized but proprietary combustor are provided for JP$8+100$ and a Fischer-Tropsch- (FT-) derived fuel and a blend of $50 \%$ each by volume.

The test data presented are part of a more extensive data set where combustion parameters were varied over a range of values. The data, herein, are for the case of nominal inlet conditions at $225 \mathrm{psia}$ and $800^{\circ} \mathrm{F}(1.551 \mathrm{MPa}$ and $700 \mathrm{~K})$, and JP-8+100 is taken as baseline. These data provide the following results.

(1) Combustor performance efficiencies at $0 \%$ FT (JP8 ), at $50 \%$ blended FT and JP- 8 , and at $100 \%$ FT are nearly identical at about $99.9 \%$. 


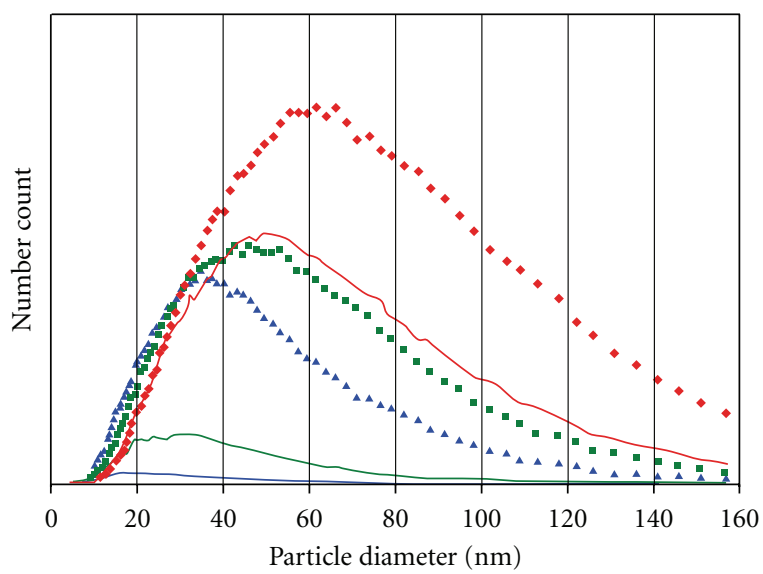

$\begin{array}{ll}\text { - JP-8 idle } & - \text { SYN idle } \\ \text { - JP-8 30\% } & - \text { SYN 30\% } \\ \text { - JP-8 75\% } & - \text { SYN 75\% }\end{array}$

FIGURE 28: Variation of particulate distribution with fueling changes (alternative fuels PW 308 engine testing).

(2) Both outer and inner wall temperatures, on average, run

(a) warmer at $F / A=0.010$ by $10^{\circ} \mathrm{F}\left(6^{\circ} \mathrm{C}\right)$ with FT fueling;

(b) cooler at $F / A=0.015$ by $20^{\circ} \mathrm{F}\left(11^{\circ} \mathrm{C}\right)$ with FT fueling;

(c) cooler at $F / A=0.02(0.019)$ by $45^{\circ} \mathrm{F}\left(25^{\circ} \mathrm{C}\right)$ with FT fueling.

(3) Sidewall temperature TSWFD ranges are 5.6\%, 2.1\%, and $1.4 \%$ higher for FT fueling for $F / A=0.01,0.015$, and 0.02 , respectively. This may relate to the flame front moving away from the fuel injection interface.

(4) Rake temperatures show core flow generally higher with FT than with JP-8, but one rake thermocouple (TC) was lost during testing, which inhibits conclusiveness.

(5) All temperatures increase with $F / A$.

(6) The $50: 50$ blend test results generally are between JP8 and FT and somewhat closer to FT.

(7) Lean blow-out (LBO) and ignition (IGN) tests were not part of the planned test program, yet observations made during startup and shutdown procedures were consistent with previous JP- $8+100$ testing. For a limited data set at a nominal 5\% combustor pressure drop, the $F / A$ for LBO is nearly $40 \%$ of the IGN $F / A$ for both $100 \%$ FT and JP-8+100. On the average, $(F / A)_{\text {LBO } 100 \% \mathrm{FT}} /(F / A)_{\mathrm{LBO} J P-8+100}<1$, with some sensitivity to percent combustor pressure drop, and $(F / A)_{\mathrm{IGN} 100 \% \mathrm{FT}} /(F / A)_{\mathrm{IGN} \mathrm{JP}-8+100}<1$. Definitive values at lower percent combustor pressure drops are insufficient for conclusions.

(8) Altitude relight, ignition, and LBO testing programs remain to be carried out.
(9) High-speed photographs of the combustion process provide some insights for CFD analysts as well as heuristic information for combustor designers. For example, there was decreased luminosity with FT versus JP-8, and clips show enhanced vorticity for the conditions cited in Table 1.

\section{Part B: Combustor Emissions}

Part $\mathrm{B}$ presents gaseous emissions as $\mathrm{CO}_{2}, \mathrm{CO}$, and $\mathrm{NO}_{x}$ (which also includes smoke and luminosity data), particulate emissions including distribution, and a brief comparison to small and large engine testing results from other programs. The emissions data are taken for the same tests and test conditions cited in PART A, nominally 225 psia at $800^{\circ} \mathrm{F}$ $(1.551 \mathrm{MPa}$ at $700 \mathrm{~K})$ with the sampling probe located at the nozzle exit plane. Emissions have a direct impact on aviation climatic constraints based on life-cycle analysis (LCA) of fueling feedstocks, which includes fueling development and engine emissions. Herein the testing is directed toward fuel flex engine combustors, providing basic data for LCA fueling evaluations, where combustor $\mathrm{A}$ is one of several to be evaluated in development of fuel-flexible engine combustors.

3.1. Gaseous Emissions. Measurements for $\mathrm{NO}_{x}$ were determined from combining $\mathrm{NO}$ and $\mathrm{NO}_{2}$ measurements (Figures $11(\mathrm{a})$ and 11(b)). Nitric oxide (NO) with molecular atomic dimension $(0.115 \mathrm{~nm})(\mathrm{NO})$, while less than JP-8 at $F / A=$ 0.010 , steadily increases to become marginally higher than JP-8 at $F / A=0.020$ (extrapolated) (Figure 11(a)). Nitrogen dioxide $\left(\mathrm{NO}_{2}\right)(0.221 \mathrm{~nm})$ (ppm) for FT or 50:50 blended fueling is considerably higher than for JP-8 and generally increases with $F / A$. Combining nitrogen dioxide (ppm) and nitric oxide (ppm), the trend with $F / A$ and fuel composition is similar to that seen for $\mathrm{NO}$; a slight decrease in $\mathrm{NO}_{2}$ : less than JP-8 at $F / A=0.010$ and marginally higher than JP-8 at $F / A=0.020$ (Figure 11(c)).

Regarding the variation of $\% \mathrm{CO}_{2}(0.0116 \mathrm{~nm}), \mathrm{ppm} \mathrm{CO}$, and $\% \mathrm{O}_{2}$, (Figures 12, 13, and 14, resp.), whereas each is strongly dependent with increasing $F / A$, the increase in $\%$ $\mathrm{CO}_{2}$ and ppm $\mathrm{CO}$ and the decrease in $\% \mathrm{O}_{2}$ are marginally consistent with varied dependencies on fuel composition. The $\% \mathrm{CO}_{2}$ appears somewhat consistent with decreased $\% \mathrm{CO}$ and $\mathrm{O}_{2}$ with fueling changes from JP-8 to FT, in agreement with flame temperature (Figure 2).

Figure 12 shows the strong variation of $\% \mathrm{CO}_{2}$ with $F / A$, but it is nearly independent of fuel composition. However, it appears somewhat consistent with decreased \% $\mathrm{O}_{2}$ with fueling changes from JP-8 to FT. Carbon monoxide $(0.113 \mathrm{~nm})(\mathrm{CO})$ generally is lower with fueling from JP-8 to FT with some changes at $F / A=0.019$, which extrapolated is unresolved (Figure 13). The decrease in $\% \mathrm{O}_{2}$ (Figure 14) is consistent with increasing $F / A$ - as well as higher rake temperatures-with FT, indicating increased combustion temperatures with more complete combustion (Figure 2).

3.2. Smoke and Photodiode Numbers. The smoke number $(\mathrm{SN})$ is dimensionless $[(\mathrm{mg}-\mathrm{C}) / \mathrm{s} /(\mathrm{kg}$-combustor gas $) / \mathrm{s}]$. It 


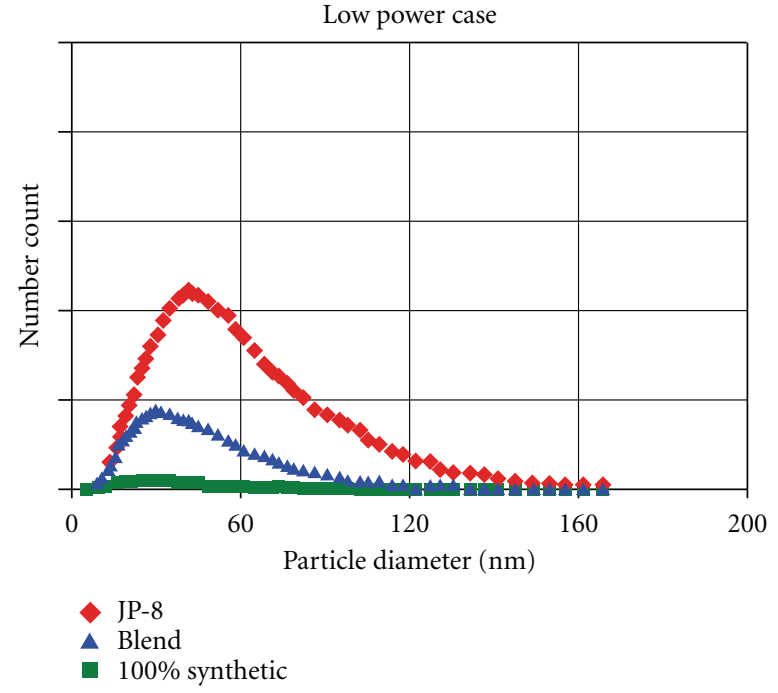

(a)

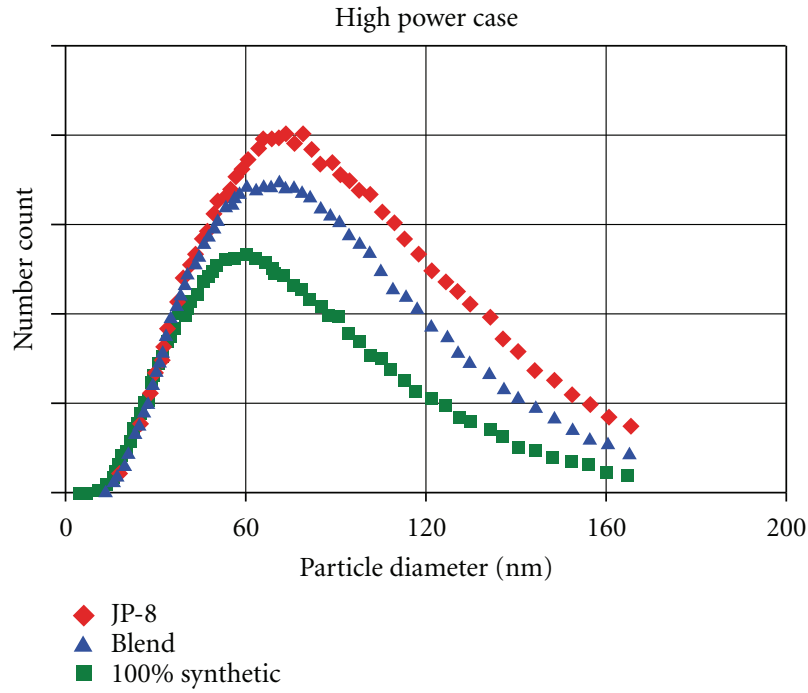

(b)

FIGURE 29: Changes in particulate distribution with power and fueling (alternative fuels PW 308 engine testing).

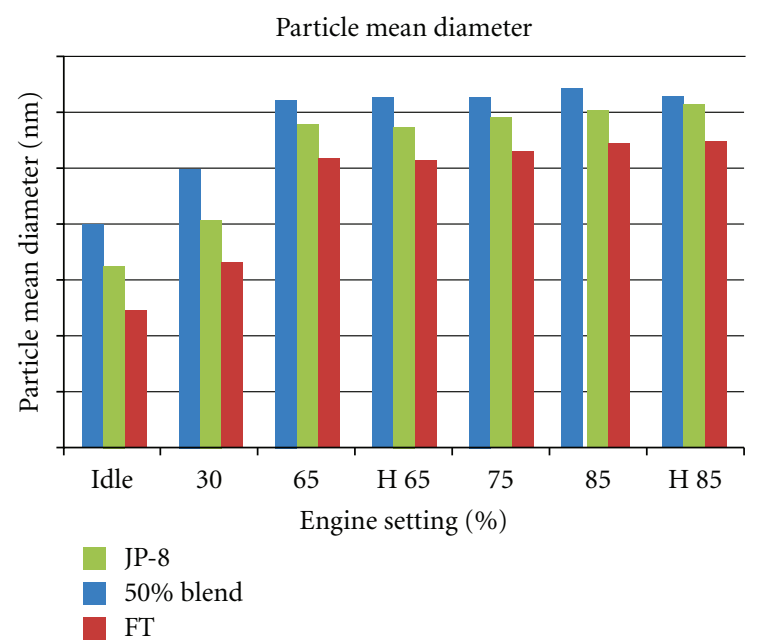

FIGURE 30: Variations of mean particulate diameter with fueling and power level (alternative fuels PW 308 engine testing).

is measured by drawing a sample of exhaust through a filter paper, then comparing the change in the reflectance between the "non-stained" and "stained" paper. Smoke number, $\mathrm{NO}_{x}$, $\mathrm{CO}$, and HC measurements are all made in the exhaust plane. Representative averages are provided to certificating authorities at several engine operating conditions. The general trend of total hydrocarbon emissions (THC) (Figure 15) strongly depends on fuel : air ratio $F / A$ and is less dependent on fuel blend except with FT at $F / A=0.015$. The reason is not known at this time, nor is it entirely clear that for all intents and purposes why THC is nearly independent of fuel composition because the smoke data do show more distinctive trends with fueling composition at $F / A=0.010$ (Figure 16). For FT fueling, the smoke number is well below that of JP-8 at F/A of 0.01 and 0.02 , yet they are nearly the same at $F / A=0.015$. FT smoke number increases with $F / A$, but it is not clear for either JP-8 or 50:50 blended fuel.

Smoke number and THC results reinforce the necessity for good particulate measurements, their distribution, composition, and toxicology.

Figure 17 illustrates the change in flame luminosity on a relative basis as the blend of JP- 8 and FT fuel is varied. Optical access windows are combustor pressure limited, and the data set shown is at $(P, T)_{\text {inlet }}\left(75 \mathrm{psia}(0.517 \mathrm{MPa}), 500^{\circ} \mathrm{F}\right.$ $(533 \mathrm{~K}))$ at $3 \%$ combustor pressure drop.

The increase in flame luminosity follows the same trends for collected smoke data as shown in Figure 18. The decline in smoke number with increasing FT fueling is most pronounced at lower $F / A$ values. Smoke number consistently increases with $F / A$ independently of fueling and yet is lowest at $100 \%$ FT fueling. A striking feature is the decrease in relative flame luminosity as illustrated in Figure 17 with the characteristic clean blue flame at 100\% FT fueling. This increase in smoke number and flame luminosity as the fuel blend is increased to $100 \%$ JP- 8 suggests that the radiation heat load on the combustor increases as well at higher $F / A$ values; the wall metal temperatures corroborate this increase.

Figure 18 illustrates a decrease in smoke number as combustor pressure changes from 175 to 225 psia (1.207 to $1.551 \mathrm{MPa}$ ) (note the anomaly at 175 psia $(1.207 \mathrm{MPa})$ ) with consistent increases in smoke number and photodiode emissions with increased $F / A$ from 0.020 to 0.025 . In general these trends corroborate the particulate data shown later.

3.3. Particulate Emissions. The particulate distribution depends on engine power setting, pressure, $F / A$, and fueling composition, and the chemical nature of the particulates and their toxicity. Such data are necessary for the determination of environmental health hazards, cloud formations, and climatic changes. 

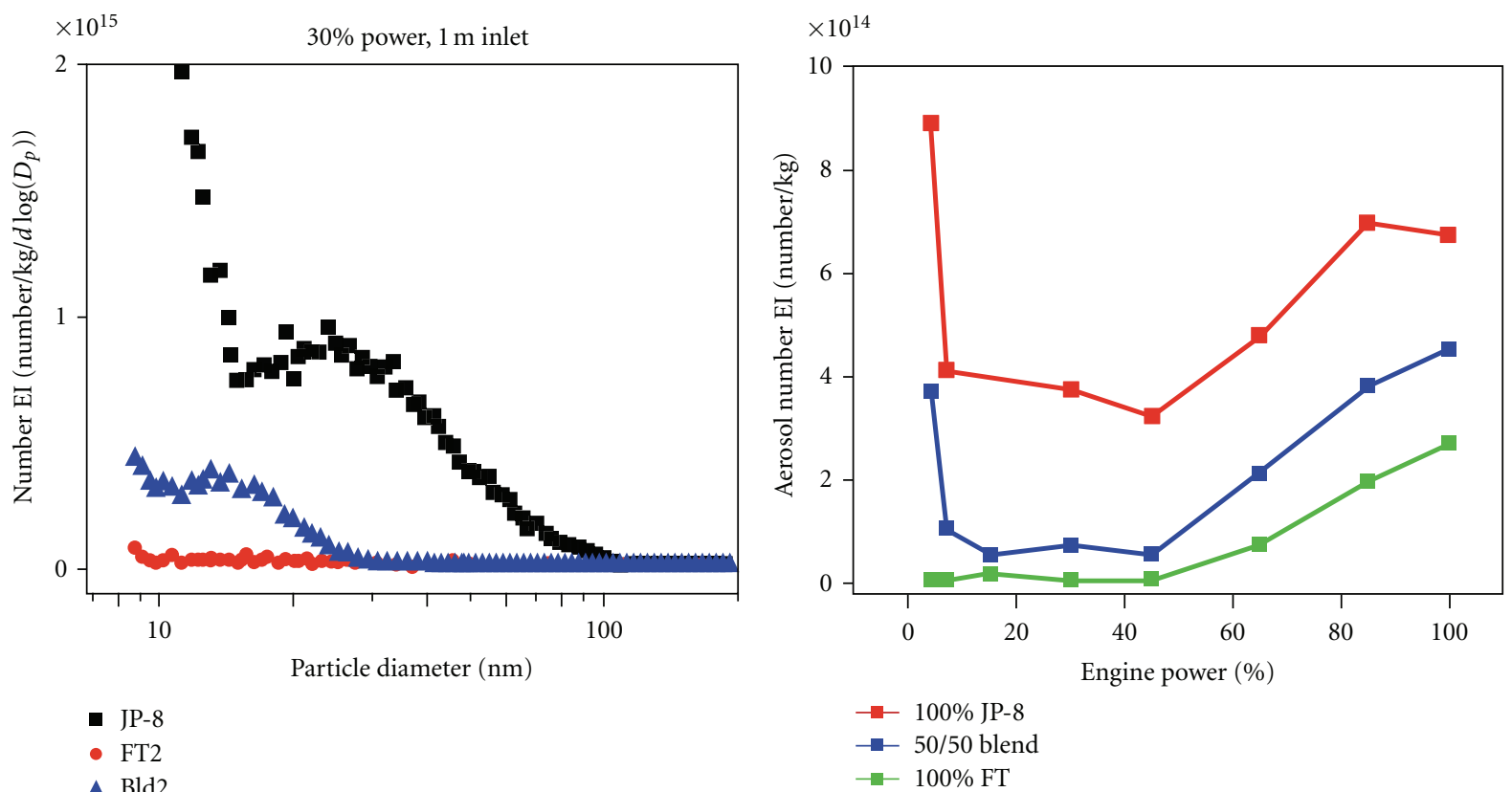

(a)

(b)
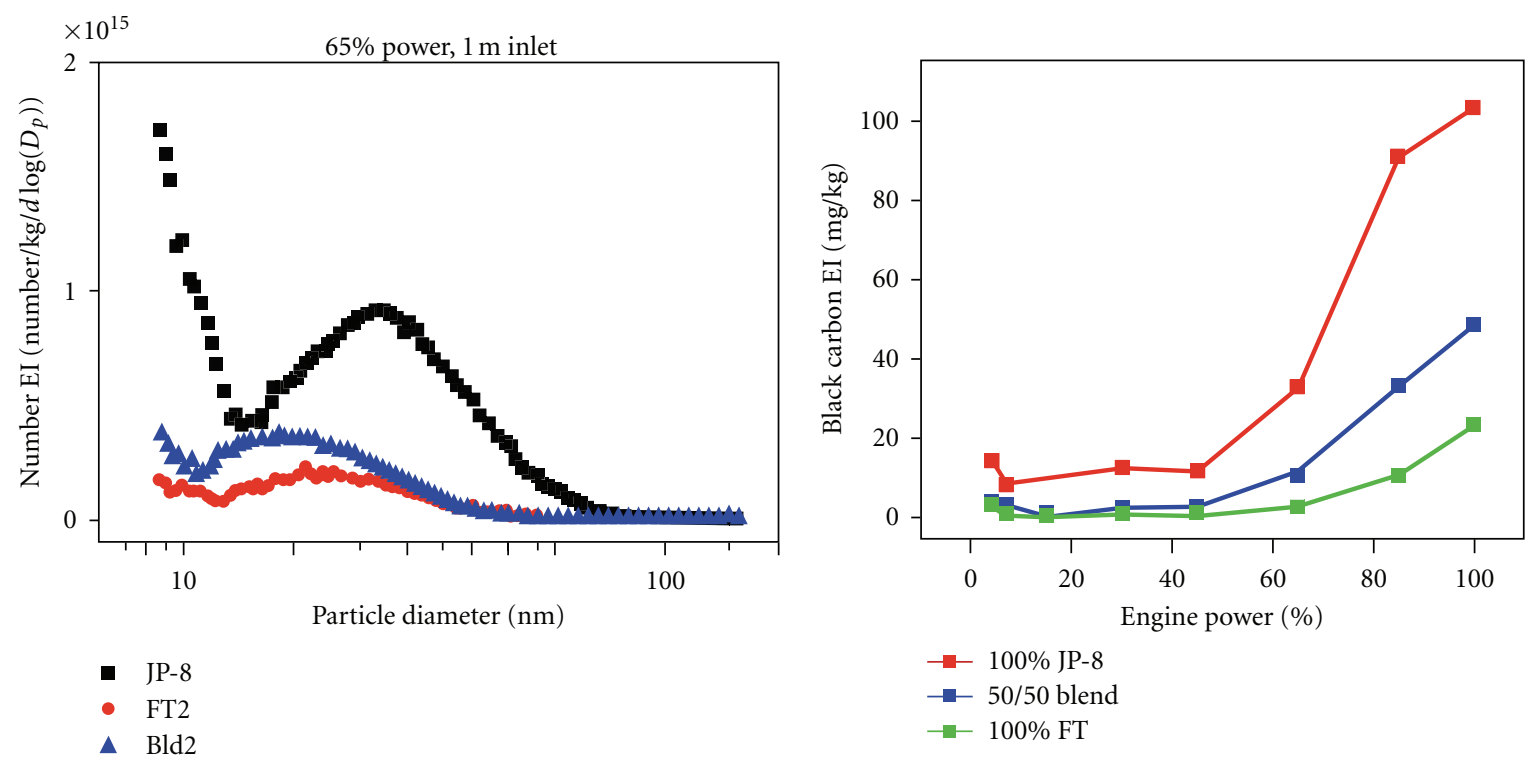

(c)

(d)

FIgURE 31: On-wing engine emissions testing measurements for particulates with JP-8, 50:50 JP-8, and S8 blend, and 100\% S8, where S8 represents an FT fueling with either coal- or gas-derived jet fuel, 1 meter downstream of exhaust plane [3].

To demonstrate the operability of the emissions probes, the test $F / A$ values were compared with the $\mathrm{CO}_{2}$-based $F / A$ values. The $100 \% \mathrm{FT}$ and $50: 50$ blends are within $+12 \%$ to $-18 \%$ of one-to-one correspondence whereas the $100 \%$ JP- 8 is $+8 \%$ to $-34 \%$ with one point at $-50 \%$. The general trends are for FT and blends to be consistently higher and JP-8 lower than one-to-one correspondence (Figure 19). Such evidence may reflect the paraffinic nature of FT and the high aromatic and cyclohydrocarbon content of JP-8.
The nitrogen gas tip-diluted, water-cooled particulate probe is illustrated in Figure 20. Because of in-plane hardware details, the photo and detail insert are shown rotated out of true exhaust plane. The probe cap outer diameter $=0.075$ in $(19 \mathrm{~mm})$ with aperture diameter 0.044 in $(1.12 \mathrm{~mm})$. The probe aperture aspirated exhausted gas steam is quenched by water cooling, which also prevents probe failures from overheating. Both diluted and undiluted probes were positioned at the combustor exhaust plane. 


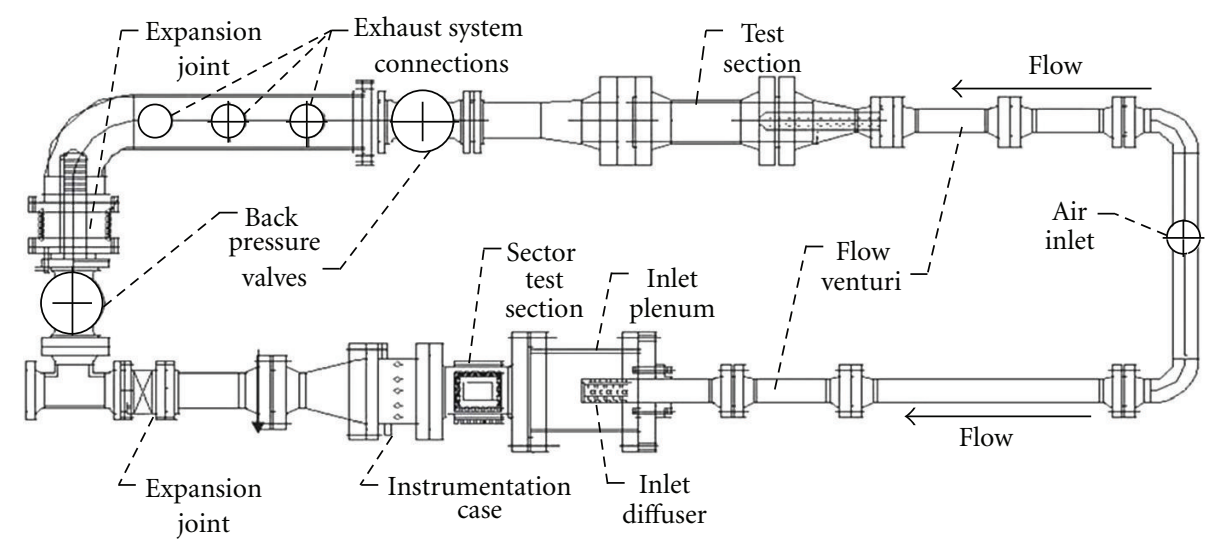

FIGURE 32: AFRL experimental test loops. The lower segment was used in the tests reported herein.

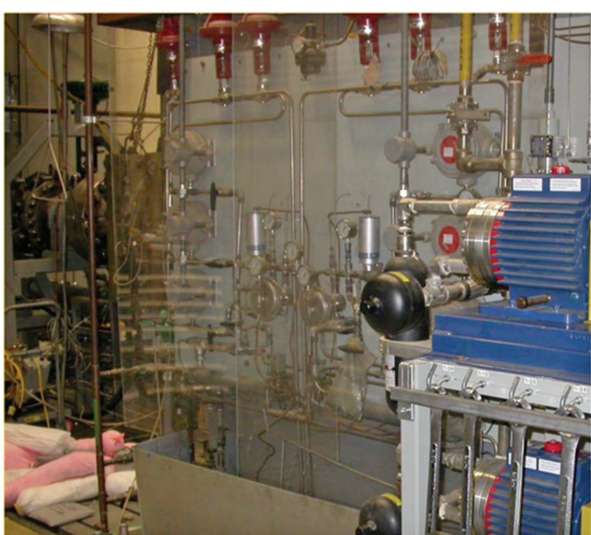

FIGURE 33: Fueling station adjacent to the test section, providing blended fueling on demand. Foreground is the main fuel pump and the secondary blending system in background.

For the dilution probe, the exhaust gas is further cooled and diluted with nitrogen gas. Both types are held above condensation temperature of water and organics en route to the instrumentation sampling panel. Details of the facility and gas emissions sampling probes are given in Shouse et al. [1].

In terms of particle emissions indices $\mathrm{EI}_{n}$, the general trends with both pressure and $F / A$ are higher $\mathrm{EI}_{n}$ values (number/kg-fuel burn) for JP-8 and lower values for FT with the $50 \%$ blend (50\% JP-8 and 50\% FT) in between (Figure 21). At an $F / A$ of 0.015 , the FT emissions index $\mathrm{EI}_{n}-\mathrm{FT}$ is nearly $1 / 4$ that of JP-8 at 175 psia $(1.207 \mathrm{MPa})$, at $F / A=0.020$, nearly $1 / 2$ at 225 psia $(1.551 \mathrm{MPa})$, and at $F / A=0.025$, nearly $7 / 8$ at 175 psia $(1.207 \mathrm{MPa})$. Note, however, the variability of $50 \%$ fuel blend at lower pressures of 75 psia $(0.517 \mathrm{MPa})$. Whereas it is difficult to make a direct comparison with on-wing engine testing, the data trends are consistent where FT particulate emissions are much lower than Jet $A$ at low power (lower engine pressure), yet the difference trend diminishes with increased engine power (higher engine pressure).
Trends with the cleaner paraffinic fuels (FT) are also reflected in terms of particulate size distribution (Figure 22) but not necessarily in terms of the FT blend, where at 75 psia $(0.517 \mathrm{MPa})$ anomalous behavior is observed, namely, the number of particulates $(N)$ of size $D_{p}$ (equivalent diameter) per cubic centimeter increases beyond that of JP-8. However, for FT fueling, the values of the $\left[d N / d\left(\log D_{p}\right)\right]$ derivative indicate that the total particle counts (integrals) are nearly half that of JP-8. Note the peak shift toward smaller diameter particulates, and the smaller (about half the size of the JP-8 peak) particulates making more difficult to detect, isolate, collect, and dispose of such particulates. Further, the toxicology requires much study.

Particulate size and, to some extent, distribution are highly dependent on the probe. Effects of probe tip dilution and probe secondary dilution are illustrated in Figure 23 for combustor pressure of $125 \mathrm{psia}(0.862 \mathrm{MPa})$ and $F / A=$ 0.015 . Here the trend with particulate size is not as definite as illustrated in Figure 22, and the effects of probe dilution diminishes with fuel blending.

Looking again at the anomalous trends at combustor pressure of 75 psia $(0.517 \mathrm{MPa})$ and $175 \mathrm{psia}(1.207 \mathrm{MPa})$ shown in Figures 21 and 22, shows similar trends in particulate distribution (Figure 24). Whereas the cleaner FT fuel particulate peak is still less than that of JP-8 or the FT blend, the trend is minor by comparison with those shown in Figure 21 at other pressures. While consistent, the behavioral reasons remain to be explored.

In contrast to the distribution trends at combustor pressure of $75 \mathrm{psia}(0.517 \mathrm{MPa})$ and $175 \mathrm{psia}(1.207 \mathrm{MPa})$ and $F / A=0.025$ (Figure 24), the trends at combustor pressure of 225 psia $(1.551 \mathrm{MPa})$ and $F / A=0.020$ are consistent with clean fuel blending; namely, JP-8 produces more particulates than the FT blend and far more than FT fueling (Figure 25). The variation with JP-8 fueling is also illustrated as JP$8(2)$ on the figure. Less pronounced is the variation in the particulate peaking which is more consistent with that of Figure 24 .

The mean particle diameter at 175 psia (1.207 MPa) decreases with fueling blend from JP-8 to FT (Figure 26). 

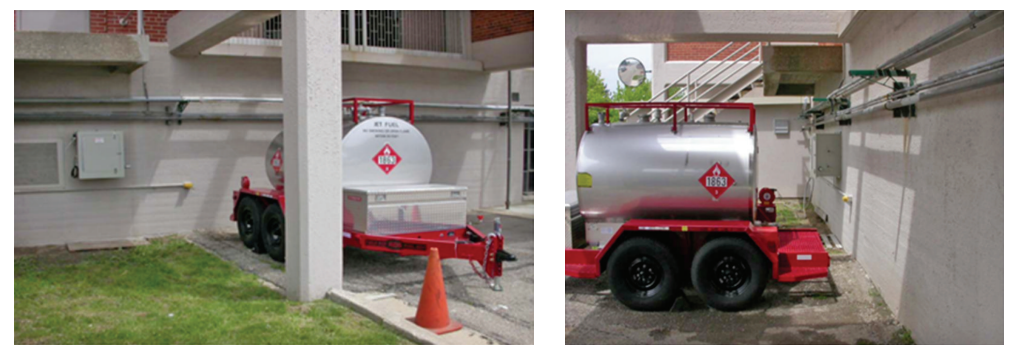

Figure 34: Photos of portable alternate fueling transport and facility supply tank.

This trend is not evident in Figure 24, adding to the complexity of predicting combustor particulate variations.

3.4. Engine Emissions Testing. Other emissions and performance tests indicate small-to-no changes in emissions within limits as prescribed in the Jet A fueling specifications [6].

A collaborative [NASA, AFRL, Arnold Engine Development Center (AEDC)/ATA, Aerodyne Research Inc. (ARI), Environmental Protective Agency (EPA), Missouri University for Science and Technology (MST), ASRC Aerospace Corp., Science Systems and Applications Inc. (SSA); University of Dayton Research Institute (UDRI), United Technologies Research Center (UTRC), Pratt-Whitney Aircraft (P\&W)], and others small and large on-wing engine emissions and performance test program provides several needed insights into aviations emissions $[7,8]$.

3.4.1. Small Engine Testing. Small-engine test stand observations on a test-stand-mounted PW 308 engine fueled by JP-8, FT, and FT-blended fuels.

\section{At Low Power}

$\mathrm{NO}_{x}$ emissions are within instrument measurement capabilities.

Lower $\mathrm{CO}$ emissions with FT/blend may be due to higher $\mathrm{H} / \mathrm{C}$ ratio.

\section{At Intermediate or High Power}

Very low CO emissions make ratios irrelevant to evaluate differences between the fuels.

There is no significant difference in $\mathrm{NO}_{x}$ emissions.

These tests also revealed negligible unburned hydrocarbons (UHC) at all power conditions for both of the two FT fuels tested. The $\mathrm{SO}_{2}$ emissions indicate the sulfur content of the blend to be around $50 \%$ of that for JP- 8 , whereas for $100 \%$ FT fuel a value of $0.1 \%$ indicates contamination.

Approximately $2 \%$ fuel flow benefit with $100 \%$ synthetic fuel can be attributed to the higher heat content of synthetic fuel. Rahmes et al. [2] provides emissions results for an unspecified fuel that was tested in a Pratt \& Whitney small turbine engine (inferred as PW 308 and biofueling). Emissions deviations were small except for core smoke
(Figure 27). The particulate distributions change with both fueling $(F / A)$ and engine power settings, showing decreases in emissions with increases in \% FT and increases with engine power setting (Figures 28 and 29). Figure 30 provides a comparison of mean particulate diameters for JP-8, 50:50 blend, and FT fueling with changes in engine power for the PW 308 off-wing engine testing.

3.4.2. Large Engine On-Wing Test Results. A consortium of agencies are working together to provide on-wing engine emissions testing for $100 \%$ JP-8 or Jet A1 (JP-8 without military additives), a 50:50 blend with SPK, and 100\% SPK engine fueling at various power settings. Here SPK represents different Fischer-Tropsch fuels depending on feedstock and refiner. Future testing will include biomass feedstock fueling (HRJ). For these tests, the fuel was either coal- or gas-derived jet fuel. Particulate distributions given by Anderson [3] at $30 \%$ and $65 \%$ engine power setting are provided on the left side of Figure 31. The number of particulates and black carbon values are provided on the right side of Figure 31.

The data presented herein show a strong dependence on $F / A$ and blend with an implied less dependency on fuel composition. The small-engine test data figures are both normalized and too coarse to illustrate the dependencies for the data herein. As for the on-wing engine test results, the AAFEX program data are planned to be released in a January 2010 workshop.

Measurement precision is much better than potential errors in measurements. For example, if most of the particles are $>10 \mathrm{~nm}$ in size, the determination of EI values in the range of $(1$ to 100$) \times 10^{14} / \mathrm{kg}$ fuel burned is to about $10 \%$ precision. Similarly, the "apparent" black carbon (BC) EI of between 10 and $1000 \mathrm{mg} /(\mathrm{kg}$ fuel burned) is also to about $10 \%$ precision. However, estimate of errors can be an order of magnitude greater arising from the several factors such as [3]

(1) lack of instrument measurement specificity for black carbon (BC),

(2) lack of direct measurement approaches for BC mass,

(3) lack of standards: BC characteristics vary widely between and within combustion sources,

(4) severe particulate losses within sampling lines (e.g., $50 \%$ to $70 \%$ in a $25-\mathrm{m}$ line prior to the diagnostic instruments), 
(5) interference from background particulates, which often comprise dust and other refractory particles that do not evaporate in the combustor.

Comparisons of engine on-wing missions data [3] and combustor-sector test data herein imply (but not conclude at this time) that sector test data replicate, at least qualitatively, on-wing test data, providing both detail and insights not gained from on-wing testing, including particulate data. Post-AAFEX 2010 Workshop data [9] also show similar qualitative emissions trends for both gaseous and particulate emissions with emissions results herein, yet elude quantitative comparisons for lack of measurement scales on many of the AAFEX reported emissions data plots.

There are qualitative differences in the emissions depending on SPK alternate fueling relative to both SPK and JP-8 fueling; however, quantitative values are not given and while these differences appear to be minor, but not insignificant, the actual values remain to be demonstrated. While this feedstock dependency of the fueling may not be large, it remains to be evaluated, which in turn affects the ASTM specifications and the presumption of being feedstock agnostic.

The EPA [10] provided logarithmically transformed emissions index composites data sets for three turbofan engines with selected fueling types similar to those used for AAFEX. These data show significant changes with engine and fuel type. Sixty-four semivolatile organic compounds nalkanes and polycyclic aromatic hydrocarbons (PAH) were measured [10]. The coupled concerns over engine and fuel type may delay FT fueling certification or prompt regulation.

It should also be noted that current aircraft auxiliary power units (APUs) (2011) have significantly higher black carbon emissions than on-wing engines [3].

3.5. Conclusions: Part B. Alternate fueling testing is being carried out to determine preliminary performance, emissions, and particulates combustor sector data relative to JP-8+100 as baseline fueling, for SPK-type (e.g., FischerTropsch, FT) fuels blends and projections for testing of biofuel fuel blends leading to preliminary development of smart fueling (fuel flexible) and combustor systems for the next generation aeronautic and aeronautic-derivative gas turbine engines. Herein alternate fueling test results for a well-characterized but proprietary combustor are provided for JP-8+100, a FT-derived fuel, and a blend of $50 \%$ each by volume.

The test data presented are part of a more extensive data set where combustion parameters were varied over a range of values. The data herein are for the case of nominal inlet conditions at $75 \mathrm{psia}(0.517 \mathrm{MPa})$ to $225 \mathrm{psia}(1.551 \mathrm{MPa})$ and $800^{\circ} \mathrm{F}(700 \mathrm{~K})$, and JP- $8+100$ is taken as the baseline.

The $50: 50$ blend test performance and emissions results are generally between JP and FT and somewhat closer to FT.

Emissions. $\mathrm{CO}$ is lower with FT; $\mathrm{CO}_{2}$ is about the same; $\mathrm{NO}$ is lower with FT; $\mathrm{NO}_{2}$ is higher with FT fueling $F / A ; \mathrm{NO}_{x}$ is lower to higher with FT with $F / A ; \mathrm{O}_{2}$ decreases with $F / A$ (consistent with temperature increase) and is lower with FT with increased spread from JP-8 with $F / A$, again consistent with rake temperature; $\mathrm{HC}$ generally decreases with $F / A$, yet FT humps at 0.015. No explanation is provided.

Basic emissions show more change with $F / A$ than with JP- 8 or FT, the latter being the more significant. These results appear to agree qualitatively to on-wing engine testing. Quantitative agreement requires resolution pending data release. The other aspect is to look at how emissions change with pressure and extrapolate those results to core pressure on the ground, that is, at much higher pressures.

These comparisons and test data presented herein imply-yet at this time cannot conclude-that sector test data replicate, at least qualitatively, on-wing test data, providing both detail and insights not gained from on-wing tests. Post-AAFEX 2010 Workshop analysis of released data and data herein is warranted.

Comparisons of engine on-wing test data [3] and combustor-sector test data herein imply (but not conclude at this time) replicate, at least qualitatively, on-wing test data, for both gaseous emissions and particulate results, providing both detail and insights not gained from on-wing tests. PostAAFEX 2010 Workshop data [9] also show similar qualitative emissions trends with results herein, yet elude quantitative comparisons for lack of scales on many of the AAFEX reported data.

SPK and JP-8 emissions profiles are qualitatively similar, yet there are observable differences in the emissions depending on alternate fueling feedstock and engine type; however, quantitative AAFEX values are not provided and remain to be demonstrated. This feedstock dependency makes it more difficult for ASTM to certify as fuel feedstock agnostic and may require conformity to more strict ASTM fuel requirements.

It should also be noted that current aircraft APU's (2011) have significantly higher black carbon emissions than onwing engines [3].

\section{Appendices}

\section{A. Fuel Specifications}

See Tables 2 and 3.

\section{B. Test Facility Conditions, and Operations, Schematic and Fueling System (See Figures 32, 33, and 34)}

The facility test conditions were as follows.

(i) Pressure: $75,125,175$, and 225 psia $(0.52,0.86,1.21$, and $1.55 \mathrm{MPa}$ ).

(ii) Temperature: $500,625,725$, and $790^{\circ} \mathrm{F}(367,658$, and $694 \mathrm{~K})$.

(iii) Pressure drops across combustor: $-3 \%, 4 \%$, and $5 \% \Delta P$.

(iv) Fuel blends: 100\% JP-8, $50: 50$, and 100\% FT. 
TABle 2: Fuel specifications for FT fuel, AFRL no. 5172-6: Lab report 2007LA06946001.

\begin{tabular}{|c|c|c|}
\hline Method & Test & Result \\
\hline ASTM D 3242-05 & Total acid number (mg KOH/g) & 0.002 \\
\hline ASTM D 1319-05 & Aromatics (\% vol) & 0.0 \\
\hline ASTM D 3227-04a & Mercaptan sulfur (\% mass) & 0.000 \\
\hline ASTM D 4294-03 & Total sulfur (\% mass) & 0.00 \\
\hline \multirow[t]{9}{*}{ ASTM D 86-07a } & Distillation & \\
\hline & Initial boiling point $\left({ }^{\circ} \mathrm{C}\right)$ & 148 \\
\hline & $10 \%$ recovered $\left({ }^{\circ} \mathrm{C}\right)$ & 162 \\
\hline & $20 \%$ recovered $\left({ }^{\circ} \mathrm{C}\right)$ & 163 \\
\hline & $50 \%$ recovered $\left({ }^{\circ} \mathrm{C}\right)$ & 169 \\
\hline & $90 \%$ recovered $\left({ }^{\circ} \mathrm{C}\right)$ & 185 \\
\hline & End point $\left({ }^{\circ} \mathrm{C}\right)$ & 198 \\
\hline & Residue (\% vol) & 0.9 \\
\hline & Loss (\% vol) & 1.1 \\
\hline ASTM D 93-07 & Flash point $\left({ }^{\circ} \mathrm{C}\right)$ & 44 \\
\hline ASTM D 4052-96 & API gravity at $60^{\circ} \mathrm{F}$ & 60.5 \\
\hline ASTM D 5972-05 & Freezing point $\left({ }^{\circ} \mathrm{C}\right)$ & -54 \\
\hline ASTM D 445-06 & Viscosity at $-20^{\circ} \mathrm{C}\left(\mathrm{mm}^{2} / \mathrm{s}\right)$ & 2.6 \\
\hline ASTM D 3338-05 & Net heat of combustion (MJ/kg) & 44.2 \\
\hline ASTM D 3343-05 & Hydrogen content (\% mass) & 15.6 \\
\hline ASTM D 1322-97 & Smoke point $(\mathrm{mm})$ & 40.0 \\
\hline ASTM D 130-04 & Copper strip corrosion $\left(2 \mathrm{~h}\right.$ at $\left.100^{\circ} \mathrm{C}\right)$ & 1a \\
\hline \multirow[t]{3}{*}{ ASTM D 3241-06 } & Thermal stability at $260^{\circ} \mathrm{C}$ & \\
\hline & Change in pressure $(\mathrm{mmHg})$ & 0 \\
\hline & Tube deposit rating, visual & 1 \\
\hline ASTM D 381-04 & Existent gum $(\mathrm{mg} / 100 \mathrm{~mL})$ & $<1$ \\
\hline ASTM D 5452-06 & Particulate matter (mg/L) & 0.5 \\
\hline MIL-DTL-83133E & Filtration time $(\min )$ & 3 \\
\hline ASTM D 1094-00 & Water reaction interface rating & 1 \\
\hline ASTM D 5006-03 & FSII (\% vol) & 0.00 \\
\hline ASTM D 2624-07 & Conductivity $(\mathrm{pS} / \mathrm{m})$ & 233 \\
\hline ASTM D 5001-06 & $\begin{array}{l}\text { Lubricity test (BOCLE) wear scar } \\
\qquad(\mathrm{mm})\end{array}$ & 0.77 \\
\hline ASTM D 4809-06 & Net heat of combustion (MJ/kg) & 44.2 \\
\hline MIL-DTL-83133E & Workmanship & Pass \\
\hline
\end{tabular}

The general operating procedures followed are the following.

(i) Set the appropriate pressure, temperature, and combustor pressure drop $\left(D_{P}\right)$ with JP-8, and collect data set.

(ii) Adjust the alternative fuel system pressure.

(iii) Blend the alternative test fuel to the appropriate ratio based on mass flow, and collect data.

(iv) Adjust the ratio mass flow accordingly, and collect data.

Instrumentation controls and characterization data available in testing are as follows:

(i) optical access into combustion chamber,
TABLE 3: Fuel specifications for AFRL no. B18-JP-8+100: Lab report 2009LA16176001 [ASTM-D 1332 smoke point was greater than $40.00 \mathrm{~mm}]$.

\begin{tabular}{|c|c|c|}
\hline Method & Test & Result \\
\hline ASTM D 3242-08 & Total acid number (mg KOH/g) & 0.003 \\
\hline ASTM D 1319-08 & Aromatics (\% vol) & 18.5 \\
\hline ASTM D 3227-04a & Mercaptan sulfur (\% mass) & 0.000 \\
\hline ASTM D 4294-08a & Total sulfur (\% mass) & 0.05 \\
\hline \multirow[t]{9}{*}{ ASTM D 86-08 } & Distillation & \\
\hline & Initial boiling point $\left({ }^{\circ} \mathrm{C}\right)$ & 160 \\
\hline & $10 \%$ recovered $\left({ }^{\circ} \mathrm{C}\right)$ & 178 \\
\hline & $20 \%$ recovered $\left({ }^{\circ} \mathrm{C}\right)$ & 163 \\
\hline & $50 \%$ recovered $\left({ }^{\circ} \mathrm{C}\right)$ & 203 \\
\hline & $90 \%$ recovered $\left({ }^{\circ} \mathrm{C}\right)$ & 240 \\
\hline & End point $\left({ }^{\circ} \mathrm{C}\right)$ & 261 \\
\hline & Residue (\% vol) & 1.3 \\
\hline & Loss (\% vol) & 0.8 \\
\hline ASTM D 93-08 & Flash point $\left({ }^{\circ} \mathrm{C}\right)$ & 46 \\
\hline ASTM D 4052-96 & API gravity at $60^{\circ} \mathrm{F}$ & 46.0 \\
\hline $\begin{array}{l}\text { ASTM D } \\
5972-05 \mathrm{e} 1\end{array}$ & Freezing point $\left({ }^{\circ} \mathrm{C}\right)$ & -50 \\
\hline ASTM D 445-06 & Viscosity at $-20^{\circ} \mathrm{C}\left(\mathrm{mm}^{2} / \mathrm{s}\right)$ & 4.2 \\
\hline ASTM D 3338-08 & Net heat of combustion (MJ/kg) & 43.3 \\
\hline ASTM D 3343-05 & Hydrogen content (\% mass) & 13.8 \\
\hline ASTM D 1322-08 & Smoke point $(\mathrm{mm})$ & 26.0 \\
\hline ASTM D 130-04 & Copper strip corrosion $\left(2 \mathrm{~h}\right.$ at $\left.100^{\circ} \mathrm{C}\right)$ & 1a \\
\hline \multirow[t]{3}{*}{ ASTM D 3241-08a } & Thermal stability at $260^{\circ} \mathrm{C}$ & \\
\hline & Change in pressure $(\mathrm{mmHg})$ & 0 \\
\hline & Tube deposit rating, visual & 1 \\
\hline ASTM D 381-04 & Existent gum $(\mathrm{mg} / 100 \mathrm{~mL})$ & 4.4 \\
\hline ASTM D 5452-08 & Particulate matter (mg/L) & 0.3 \\
\hline MIL-DTL-83133F & Filtration time (min) & 6 \\
\hline ASTM D 1094-00 & Water reaction interface rating & - \\
\hline ASTM D 5006-03 & FSII (\% vol) & 0.10 \\
\hline ASTM D 2624-07 & Conductivity $(\mathrm{pS} / \mathrm{m})$ & 498 \\
\hline ASTM D 5001-06 & $\begin{array}{l}\text { Lubricity test (BOCLE) wear scar } \\
\qquad(\mathrm{mm})\end{array}$ & - \\
\hline ASTM D 4809-06 & Net heat of combustion (MJ/kg) & - \\
\hline MIL-DTL-83133F & Workmanship & Pass \\
\hline
\end{tabular}

(ii) application of advanced laser diagnostics,

(iii) continuous low-pressure altitude capabilities,

(iv) application of advanced sensors for open- and closedloop combustion control, and

(v) characterization of advanced fuels.

\section{Estimates of Measurement Errors}

In this appendix, we provide estimates of errors in the data measurements repeatability for the combustor, on-wing, and fuel blend ratios and some additional explanations for arriving at those estimates. 
TABLE 4: Combustor outer and inner liner temperature, thermal difference data, and number and name of thermocouples (TCs) used to plot thermal profiles. ${ }^{\mathrm{a}, \mathrm{b}, \mathrm{c}}$

\begin{tabular}{|c|c|c|c|c|c|c|c|c|c|c|c|c|}
\hline \multirow{3}{*}{ TC } & & & & \multicolumn{3}{|c|}{$F / A=0.010$} & \multicolumn{3}{|c|}{$F / A=0.015$} & \multicolumn{3}{|c|}{$F / A=0.020$} \\
\hline & \multicolumn{3}{|c|}{ Unwrapped $^{\mathrm{d}}$} & JP-8 & FT & $50: 50$ & JP-8 & FT & $50: 50$ & JP-8 & FT & $50: 50$ \\
\hline & TC no. & $X$ & $\Theta$ & $\mathrm{Col} \mathrm{C}$ & $\mathrm{Col} \mathrm{G}$ & $\mathrm{Col} \mathrm{F}$ & $\mathrm{Col} \mathrm{O}$ & Col K & $\mathrm{Col} \mathrm{M}$ & Col Q & Col V & Col T \\
\hline \multicolumn{13}{|c|}{ Outer liner } \\
\hline & & & 0.00 & & & & & & & & & \\
\hline TOLAL & 22 & 0.94 & 0.20 & 817 & 825 & 825 & 852 & 850 & 846 & 882 & 873 & 881 \\
\hline TOLFL & 20 & 0.00 & 0.22 & 900 & 904 & 907 & 968 & 935 & 946 & 1030 & 971 & 1002 \\
\hline TOLML & 21 & 0.67 & 0.26 & 861 & 870 & 869 & 927 & 924 & 925 & 987 & 957 & 985 \\
\hline TOLMWA & 24 & 0.19 & 0.32 & 870 & 875 & 878 & 962 & 917 & 944 & 1027 & 960 & 1002 \\
\hline TOLFM & 27 & 0.00 & 0.34 & 899 & 902 & 908 & 983 & 944 & 956 & 1060 & 985 & 1024 \\
\hline TOLCA & 25 & 1.00 & 0.52 & 862 & 872 & 872 & 920 & 910 & 912 & 986 & 952 & 974 \\
\hline TOLAM & 28 & 0.94 & 0.58 & 814 & 825 & 825 & 852 & 851 & 850 & 888 & 874 & 886 \\
\hline TOLMR & 36 & 0.67 & 0.62 & 873 & 887 & 884 & 953 & 918 & 941 & 1013 & 955 & 996 \\
\hline TOLFR & 34 & 0.00 & 0.74 & 887 & 888 & 891 & 965 & 924 & 944 & 1016 & 956 & 1001 \\
\hline TOLMWI & 23 & 0.33 & 0.79 & 879 & 879 & 884 & 933 & 905 & 914 & 992 & 937 & 969 \\
\hline TOLAR & 37 & 0.84 & 0.86 & 831 & 843 & 843 & 877 & 872 & 874 & 917 & 906 & 922 \\
\hline TSWFD & 41 & 0.22 & 0.97 & 1218 & 1288 & 1280 & 1438 & 1469 & 1444 & 1544 & 1565 & 1581 \\
\hline TSWFT & 30 & 0.78 & 1.00 & 814 & 820 & 820 & 847 & 836 & 841 & 854 & 842 & 850 \\
\hline \multicolumn{13}{|c|}{ Inner liner } \\
\hline TILMWI & 38 & 0.50 & 1.20 & 897 & 908 & 906 & 994 & 969 & 976 & 1091 & 1023 & 1066 \\
\hline TILFR & 35 & 0.00 & 1.23 & 890 & 917 & 919 & 995 & 959 & 967 & 1075 & 1006 & 1050 \\
\hline TILMWO & 26 & 0.50 & 1.33 & 902 & 908 & 909 & 988 & 962 & 968 & 1096 & 1025 & 1071 \\
\hline TILCA & 29 & 1.00 & 1.50 & 1056 & 1065 & 1058 & 1229 & 1217 & 1219 & 1411 & 1326 & 1348 \\
\hline \multirow[t]{2}{*}{ TILFL } & 39 & 0.00 & 1.54 & 913 & 917 & 916 & 1002 & 970 & 981 & 1098 & 1030 & 1069 \\
\hline & & & 2.00 & & & & & & & & & \\
\hline
\end{tabular}

a Geometric position accuracy of thermocouple position coordinates is estimated at $\pm 1.5 \%$.

${ }^{\mathrm{b}}$ For nominal inlet pressure $225 \mathrm{psia}(1.55 \mathrm{MPa}), 800^{\circ} \mathrm{F}(700 \mathrm{~K})$, and $3 \%$ combustor pressure drop.

'Note: Col C, G, F, K, M, Q, V, and T are data set tracking identifiers.

${ }^{\mathrm{d}} X=x / L$ (which varies from 0 to 1 ), where $x$ is the TC position measured from the liner inlet, and $L$ is the overall liner length.

$\Theta$ : circumferential TC position measured over the liner outside $y / L_{\theta}(0$ to 1$)$ and continuing back along the inside liner ( 1 to 2$)$, where $L_{\theta}$ is half the unwrapped liner "width." The normalized unwrapped coordinate $(X, \Theta)$ is the TC location $(x, y)$.

\section{C.1. Combustor Sector Experiments}

Thermal measurements: $\pm 0.5 \%$ full scale.

Flow measurements: $\pm 1 \%$.

Fuel flow measurements (turbine flow meters \pm $0.25 \%)$.

Fuel blend ratio less than $\pm 4 \%$.

Static pressure: $\pm 0.1 \%$.

Thermal rake: $\pm 0.5 \%$ to $3 \%$.

Emissions rake: $\pm 1 \%$.

Relative carbon balance: $\pm 3 \%$.

Calculated flame temperature: $\pm 3 \%$.

Particulates: $\pm 5 \%$ to $10 \%$.

Smoke number: $\pm 3 \mathrm{SN}$, where $\mathrm{SN}=[(\mathrm{mg}-\mathrm{C}) / \mathrm{s}] /$ $[($ kg-combustor gas $) / s]$.
Note 1. Thermocouple geometric placement: $\pm 1.5 \%$.

Note 2. The relative carbon balance error involves comparison of metered experimental to calculated fuel/air ratio $(F / A=F A R)$, determined from the emissions data $(\mathrm{CO}$, $\mathrm{CO}_{2}, \mathrm{HC}$, and $\mathrm{NO}_{x}$ ), per SAE Aerospace Recommended Practice (ARP) 1533 guidance [11]. The emissions analyzers are calibrated prior to every day-to-day test using certified (2\%) gas concentrations. The relative error is considered representative data (across industry), when it is between $10 \%$ and $15 \%$ (10\% for engines above idle and $15 \%$ at idle). Herein, the uncertainty in the measured raw emissions data is considered 3\%, accurate to the $2 \%$ certified gas calibrations and accounting for the combined propagated error for the analyzer specifications: 1\% full-scale reading. With multiple calibration gases the analyzers are accurate with the standard gas, repeatable (precise), such that the relative error in the carbon balance is considered accurate to $3 \%$. 
TABle 5: Combustor outer and inner liner temperature difference with respect to JP- $8+100^{\mathrm{a}}\left(T_{\text {fuel blend }}-T_{\mathrm{JP}-8}\right)\left({ }^{\circ} \mathrm{F}\right)[$ For nominal inlet pressure 225 psia $(1.55 \mathrm{MPa}), 800^{\circ} \mathrm{F}(700 \mathrm{~K})$, and $3 \%$ combustor pressure drop].

\begin{tabular}{|c|c|c|c|c|c|c|c|c|c|c|c|c|}
\hline \multirow{3}{*}{$\mathrm{TC}$} & & & & \multicolumn{3}{|c|}{$F / A=0.010$} & \multicolumn{3}{|c|}{$F / A=0.015$} & \multicolumn{3}{|c|}{$F / A=0.020$} \\
\hline & \multicolumn{3}{|c|}{ Unwrapped $^{\mathrm{c}}$} & JP-8 & FT & $50: 50$ & JP-8 & FT & $50: 50$ & JP-8 & FT & $50: 50$ \\
\hline & TC no. & $X$ & $\Theta$ & $\mathrm{Col} \mathrm{C}$ & $\mathrm{Col} \mathrm{G}$ & Col F & $\mathrm{Col} \mathrm{O}$ & $\mathrm{Col} \mathrm{K}$ & $\mathrm{Col} \mathrm{M}$ & Col Q & Col V & Col T \\
\hline \multicolumn{13}{|c|}{ Outer liner } \\
\hline \multicolumn{3}{|c|}{ Circumferential start point } & 0.00 & & & & & & & & & \\
\hline TOLAL & 22 & 0.94 & 0.20 & 0 & 8 & 8 & 0 & -2 & -6 & 0 & -9 & - \\
\hline TOLFL & 20 & 0.00 & 0.22 & 0 & 4 & 7 & 0 & -33 & -22 & 0 & -1 & -28 \\
\hline TOLML & 21 & 0.67 & 0.26 & 0 & 9 & 8 & 0 & -3 & -2 & 0 & -30 & -2 \\
\hline TOLMWA & 24 & 0.19 & 0.32 & 0 & 5 & 8 & 0 & -45 & -18 & 0 & -67 & -25 \\
\hline TOLFM & 27 & 0.00 & 0.34 & 0 & 3 & 9 & 0 & -39 & -2 & 0 & -75 & -36 \\
\hline TOLCA & 25 & 1.00 & 0.52 & 0 & 10 & 10 & 0 & -10 & -8 & 0 & -34 & -12 \\
\hline TOLAM & 28 & 0.94 & 0.58 & 0 & 11 & 11 & 0 & -1 & -2 & 0 & -14 & -2 \\
\hline TOLMR & 36 & 0.67 & 0.62 & 0 & 14 & 11 & 0 & -35 & -12 & 0 & -58 & -17 \\
\hline TOLFR & 34 & 0.00 & 0.74 & 0 & 1 & 4 & 0 & -41 & -21 & 0 & -60 & -15 \\
\hline TOLMWI & 23 & 0.33 & 0.79 & 0 & 0 & 5 & 0 & -28 & -19 & 0 & -55 & -23 \\
\hline TOLAR & 37 & 0.84 & 0.86 & 0 & 12 & 12 & 0 & -5 & -3 & 0 & -11 & 5 \\
\hline TSWFD & 41 & 0.22 & 0.97 & 0 & 70 & 62 & 0 & 31 & 6 & 0 & 21 & 37 \\
\hline TSWFT & 30 & 0.78 & 1.00 & 0 & 6 & 6 & 0 & -11 & -6 & 0 & -12 & -4 \\
\hline \multicolumn{13}{|c|}{ Inner liner } \\
\hline TILMWI & 38 & 0.50 & 1.20 & 0 & 11 & 9 & 0 & -25 & -18 & 0 & -68 & -25 \\
\hline TILFR & 35 & 0.00 & 1.23 & 0 & 27 & 29 & 0 & -36 & -28 & 0 & -69 & -25 \\
\hline TILMWO & 26 & 0.50 & 1.33 & 0 & 6 & 7 & 0 & -26 & -20 & 0 & -71 & -25 \\
\hline TILCA & 29 & 1.00 & 1.50 & 0 & 9 & 2 & 0 & -12 & -10 & 0 & -85 & -63 \\
\hline TILFL & 39 & 0.00 & 1.54 & 0 & 4 & 3 & 0 & -32 & -21 & 0 & -68 & -29 \\
\hline \multicolumn{3}{|c|}{ Circumferential end point } & 2.00 & & & & & & & & & \\
\hline \multicolumn{3}{|c|}{ Average without TSWFD } & & & 8 & 9 & & -23 & -14 & & -50 & -19 \\
\hline \multicolumn{3}{|c|}{ Average with TSWFD } & & & 12 & 12 & & -20 & -13 & & -46 & -16 \\
\hline \multicolumn{3}{|c|}{ Average $(($ without + with $) / 2)$} & & & 10 & 10 & & -21 & -14 & & -48 & -18 \\
\hline
\end{tabular}

${ }^{a}$ Geometric position accuracy of thermocouple position coordinates is estimated at $\pm 1.5 \%$.

${ }^{\mathrm{b}}$ Note $\Delta^{\circ} \mathrm{C}=\Delta \mathrm{K}=\Delta^{\circ} \mathrm{F} / 1.8$.

${ }^{\mathrm{c}} X=x / L$ where $x$ is the TC position measured from the liner inlet, and $L_{x}$ is the overall liner length.

$\Theta$ : circumferential TC position measured over the liner outside/ $L_{\theta}$ ( 0 to 1 ) and continuing back along inside liner ( 1 to 2 ), where $L_{\theta}$ is half the unwrapped liner "width."

Note 3. The calculated flame temperature is a thermodynamic energy balance between reactants and products, utilizing emissions data (efficiency) and experimental operating conditions; it is consistent with temperatures determined from thermocouple rakes (based on multiple experiments, to within $\pm 10^{\circ} \mathrm{F}\left( \pm 5.6^{\circ} \mathrm{C}\right)$ ), which reinforces the cited $0.5 \%$ error full scale. However, the calculated flame temperature can be no better than 3\% because it is based on efficiency, as calculated from SAE ARP 1533 [11].

\section{C.2. Estimates of Error for On-Wing Data}

Gaseous emissions $\pm 5 \%$ or better.

Black carbon (BC) number or mass $\pm 6 \%$ or better.

Particulates measurement variations [not repeatability (precision) error bands] can be large as there are no convenient methods for calibrating instruments. Nanoparticulates are lost on rake placement, probe inlets, transport tubing walls, and vary by species [3], with estimate of error:

EI Number [200\% (dirty engine (APU) and 100\% (clean engine)].

EI mass $50 \%$ to $100 \%$.

C.3. Error of Estimate for Fuel Blend. In an analysis to verify fuel blending, samples of the 50/50 blended fuel were collected just upstream of the fuel injectors. The FT fuel used to make the JP- $8+100 /$ FT blend contained no aromatics $(<0.2$ volume \%), so analysis of aromatic hydrocarbon content was used to determine the ratio of JP- $8+100$ in the JP- $8+100 / F T$ blend. The analysis was performed using ASTM D 6379. In this method, normal-phase high-performance liquid chromatography (HPLC) with refractive index detection was used. The aromatics were eluted from a cyano column $(4.6 \times 150 \mathrm{~cm})$ with hexanes as the mobile phase. Standards containing monoaromatics and diaromatics were used to 
TABLE 6: Thermocouple (TC) number and name used in plotting thermal and thermal difference profiles ${ }^{\mathrm{a}}$.

\begin{tabular}{|c|c|c|c|c|c|c|c|}
\hline \multicolumn{8}{|c|}{ Liner outer wall } \\
\hline \multicolumn{2}{|c|}{ Axial } & \multicolumn{6}{|c|}{ Circumferential } \\
\hline \multirow[b]{2}{*}{ TC no. } & \multirow[b]{2}{*}{ TC name } & \multicolumn{2}{|c|}{ Forward (FWD) } & \multicolumn{2}{|c|}{ Midplane (MID) } & \multicolumn{2}{|c|}{ Aft (AFT) } \\
\hline & & TC no. & TC name & TC no. & TC name & TC no. & TC name \\
\hline 20 & TOLFL & 20 & TOLFL & 21 & TOLML & 22 & TOTAL \\
\hline 27 & TOLFM & 27 & TOLFM & 24 & TOLMWA & 25 & TOLCA \\
\hline 24 & TOLMWA & 34 & TOLFR & 36 & TOLMR & 28 & TOLAM \\
\hline 21 & TOLML & & & 23 & TOLMWI & 37 & TOLAR \\
\hline 22 & TOLAL & & & & & & \\
\hline \multicolumn{8}{|c|}{ Liner inner wall } \\
\hline \multirow{2}{*}{\multicolumn{2}{|c|}{ Axial }} & \multicolumn{6}{|c|}{ Circumferential } \\
\hline & & \multicolumn{2}{|c|}{ Forward (FWD) } & \multicolumn{2}{|c|}{ Midplane (MID) } & \multicolumn{2}{|c|}{ Aft (AFT) } \\
\hline TC no. & TC name & TC no. & TC name & TC no. & TC name & TC no. & TC name \\
\hline 35 & TILFR & 35 & TILFR & 38 & TILMLWI & 29 & TILCA \\
\hline 26 & TILMWD & 39 & TILFL & 36 & TILMWD & & \\
\hline 29 & TILCA & & & & & & \\
\hline
\end{tabular}

calibrate the HPLC (Agilent Model 1100). Both standards and samples were diluted to the same level $(1: 50)$ in hexanes before injection into the HPLC. The refractive index peak areas were used to quantify the monoaromatics and diaromatics concentrations. These were summed to yield the total aromatics content in the fuels in volume percent. The JP-8+100 fuel sample contained 17.3 volume $\%$ aromatics, and the JP- $8+100 /$ FT blend sample contained 8.3 volume $\%$ aromatics. Thus, the ratio of JP- $8+100$ in the blend was $8.3 / 17.3$ or 0.48 , or $48 \%$ JP- $8+100$ and $52 \%$ FT to within $4 \%$.

\section{Combustor Thermal Data and Postprocessing Parameters (See Tables 4, 5, and 6)}

Thermocouple number and name used in plotting thermal and thermal difference profiles. These selected TCs provide for nominal axial and circumferential thermal and differential thermal profiles. The profiles are not aligned with mutually perpendicular coordinate locations.

\section{References}

[1] D. T. Shouse, J. S. Stutrud, and C. W. Frayne, "High pressure combustion research at the air force research laboratory," in Proceedings of the 15th International Symposium on Air Breathing Engines, Bangalore, India, 2001.

[2] T. F. Rahmes, J. D. Kinder, T. M. Henry et al., "Sustainable Bioderived Synthetic Paraffinic Kerosene (Bio-SPK) jet fuel flights and engine tests program results," in Proceedings of the 9th AIAA Aviation Technology, Integration and Operations (ATIO) Conference, Aircraft Noise and Emissions Reduction Symposium (ANERS), Reston, Va, USA, September 2009.

[3] B. Anderson, "Langley Aircraft Emission Research: Highlights and Overview of the Alternative Aviation Fuel Experi- ment," AMRD/AAFEX program presentation, NASA Langley Research Center, Hampton, Va, USA, 2009.

[4] R. C. Hendricks, D. T. Shouse, W. M. Roquemorr et al., "Experimental and Computational Study of Trapped Vortex Combustor Sector Rig With Tri-Pass Diffuser," NASA/TM2004-212507, NASA Glenn Research Center, Cleveland, Ohio, USA, 2004.

[5] R. C. Ryder, R. C. Hendricks, M. L. Huber, and D. T. Shouse, "Computational Analysis of Dynamic SPK(S8)-JP-8 Fueled Combustor-Sector Performance," ISROMAC 13, NASA Glenn Research Center, Cleveland, OH, 2010.

[6] J. D. Kinder and T. Rahmes, "Evaluation of Bio-Derived Synthetic Paraffinic Kerosenes (Bio-SPK)," Sustainable Biofuels Research \& Technology Program Document, The Boeing Company, Seattle, Wash, USA, 2009, http://www.isesd.cv.ic .ac.uk.

[7] D. Bulzan, "Alternative Aviation Fuel Experiment (AAFEX): Overview," NASA Glenn Research Center, Cleveland, Ohio, USA, 2009.

[8] NASA, AFRL, ARI, UTRC and P\&W, "Alternative Fuel Test on PW308 Engine," collaborative presentation, 2008.

[9] D. Bulzan et al., "Gaseous and particulate emissions results of the NASA alternate aviation fuel experiment (AAFEX)," in Proceedings of the ASME Turbo Expo: Power for Land, Sea and Air (GT '10), Glasgow, Scotland, June 2010, GT2010-23524.

[10] J. S. Kinsey, M. D. Hays, Y. Don, D. C. Williams, and R. Logan, "Chemical characterization of the fine particle emissions from commercial aircraft engines during the aircraft particle emissions experiment (APEX) 1 to 3," Environmental Science Technology, vol. 45, no. 8, pp. 3415-3421, 2011.

[11] SAE International, "Procedure for the Analysis and Evaluation of Gaseous Emissions from Aircraft Engines," Aerospace Recommended Practice 1533A, 2004. 

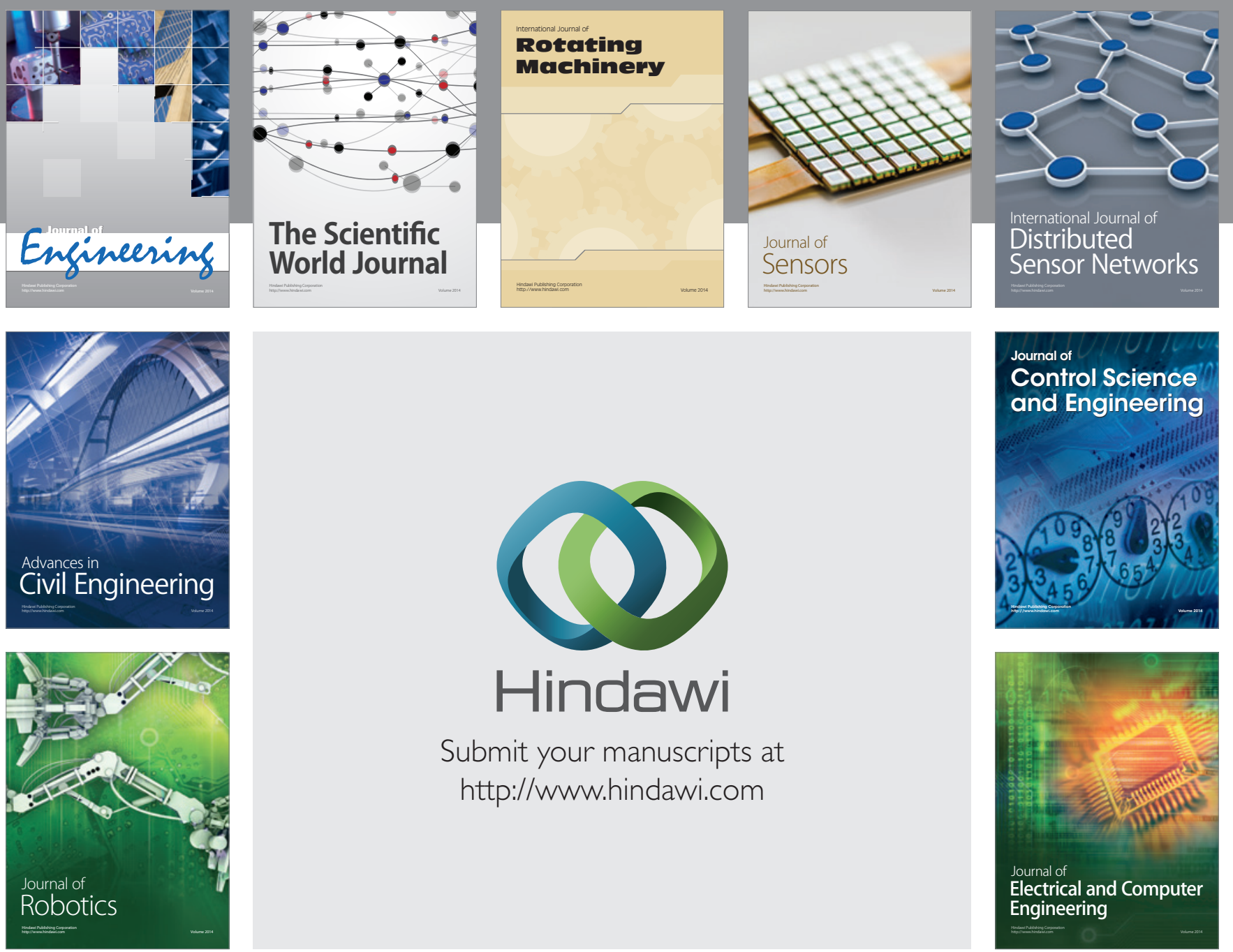

Submit your manuscripts at

http://www.hindawi.com
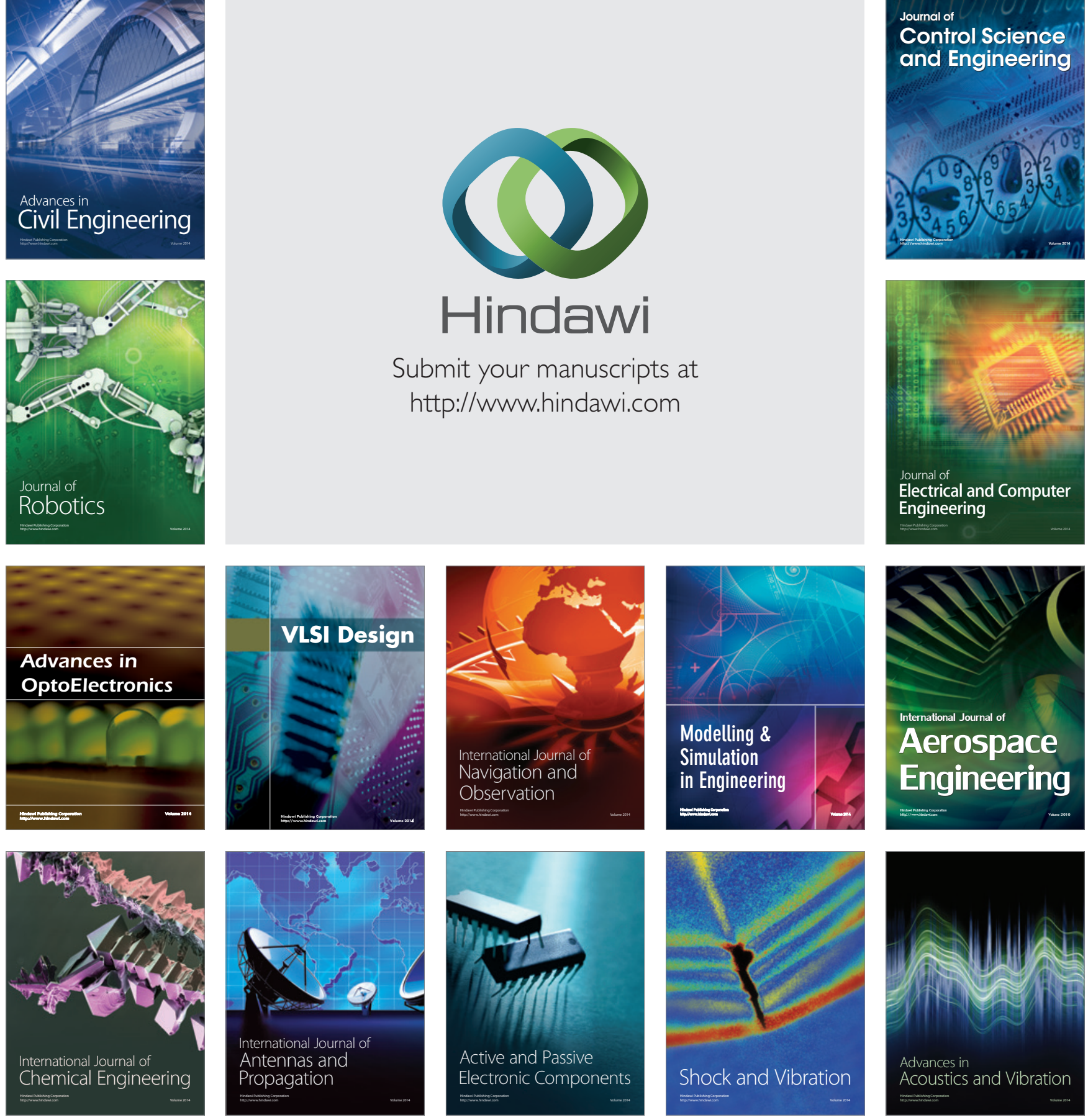